\title{
Risk Management for Monetary Policy Near the Zero Lower Bound
}

ABSTRACT With projections showing inflation heading back toward target and the labor market continuing to improve, the Federal Reserve has begun to contemplate an increase in the federal funds rate. There is, however, substantial uncertainty around these projections. How should this uncertainty affect monetary policy? In many standard models uncertainty has no effect. In this paper, we demonstrate that the zero lower bound (ZLB) on nominal interest rates implies that the central bank should adopt a looser policy when there is uncertainty. In the current context this result implies that a delayed liftoff is optimal. We demonstrate this result theoretically through two canonical macroeconomic models. Using numerical simulations of our models calibrated to the current environment, we find that optimal policy calls for a delay in liftoff of two to three quarters relative to a policy that does not take into account uncertainty about policy being constrained by the ZLB. We then use a narrative study of Federal Reserve communications and estimated policy reaction functions to show that risk management is a long-standing practice in the conduct of monetary policy.

\footnotetext{
T o what extent should uncertainty affect monetary policy? This classic question is relevant today as the Federal Reserve considers when to start increasing the federal funds rate. In the March 2015 "Summary of Economic Projections," most Federal Open Market Committee (FOMC) participants forecast that the unemployment rate would return to its longrun neutral level by late 2015 and that inflation would gradually rise, returning to its 2 percent target. This forecast could go wrong in two ways. First, the FOMC may be overestimating the underlying strength in the economy or the tendency of inflation to return to target. Guarding against these risks
} 
would call for cautious removal of accommodation. Second, the economy could be poised for stronger growth and inflation than currently projected. This second risk would call for more aggressive rate hikes. How should policy manage these divergent risks?

If the FOMC misjudges the impediments to growth and inflation and reduces monetary accommodation too soon, it could find itself in the uncomfortable position of having to reverse course and being constrained by the zero lower bound (ZLB) again. It is true that the FOMC has access to unconventional policy tools at the ZLB, but these appear to be imperfect substitutes for the traditional funds rate instrument. In contrast, if the Fed keeps rates too low and inflation rises too quickly, most likely inflation could be brought back into check with modest increases in interest rates. Since the unconventional tools available to counter the first scenario may be less effective than the traditional tools available to counter the second scenario, the costs of premature liftoff may exceed those of delay. It therefore seems prudent to refrain from raising rates until the FOMC is highly certain that growth is sustainable and inflation is returning to target. ${ }^{1}$

In this paper we establish theoretically that uncertainty about monetary policy being constrained by the ZLB in the future implies an optimally looser policy today, which in the current context means delaying liftoffthe risk management framework just described. We formally define risk management as the principle that policy should be formulated taking into account the dispersion of shocks around their means. Our main theoretical contribution is to provide a simple demonstration, using standard models of monetary policy, that the ZLB implies a new role for such risk management through two distinct economic channels.

The first channel, which we call the expectations channel, arises because the possibility of a binding ZLB tomorrow leads to lower expected inflation and output today, and hence dictates some counteracting policy easing today. The second channel, which we call the buffer stock channel, arises because, if inflation or output is intrinsically persistent, building up output or inflation today reduces the likelihood and severity of hitting the ZLB tomorrow. Optimal policy when either of these channels is operative should be looser whenever a return to the ZLB remains a distinct possibility. In simulations calibrated to the current environment, we find that optimal policy prescribes two to three quarters of delay in liftoff relative to a policy that does not take this uncertainty into account. However, under the

1. In his speech at the Petersen Institute for Economics, Evans (2014) discussed these issues at greater length. 
optimal policy the central bank must also be prepared to raise rates quickly as the threat of being constrained by the ZLB recedes.

Would it be unusual for the Fed to take uncertainty into account in setting its policy rate? The second part of this paper argues that risk management has been a long-standing practice in U.S. monetary policy. Therefore, advocating it in the current policy environment would be consistent with a well-established approach of the Federal Reserve. Of course, because the ZLB was only recently perceived as an important constraint, the theoretical rationales for risk management were different in the past. It is true that in a wide class of models that abstract from the ZLB, optimal policy involves adjusting the interest rate in response to the mean of the distribution of shocks, and information on higher moments is irrelevant (the so-called "certainty equivalence" principle). However, there is an extensive literature covering departures from this result based on nonlinear economic environments or uncertain policy parameters that justify taking a risk management approach away from the ZLB.

We explore whether policymakers actually practiced risk management prior to the ZLB period in two ways. First, we analyze Federal Reserve communications over the period 1987-2008 and find numerous examples when uncertainty or the desire to insure against important risks to the economy were used to help explain the setting of policy. Confirmation of this view is found in the statements of Alan Greenspan, who during his tenure as Federal Reserve chair noted, "the conduct of monetary policy in the United States has come to involve, at its core, crucial elements of risk management."'2 Second, we estimate a conventional forecast-based monetary policy reaction function augmented with a variety of measures of risk based on financial market data, Federal Reserve Board staff forecasts, private-sector forecasts, and narrative analysis of the FOMC minutes. We find clear evidence that when measured in this way, risk has had a statistically and economically significant impact on the interest rate choices of the FOMC. For the FOMC, risk management appears to be old hat.

If the monetary policy toolkit contained alternative instruments that were perfect substitutes for changing the policy rate, then the ZLB would not present any special economic risk and our analysis would be moot. We do not think this is the case. Even though most central bankers believe unconventional policies such as large-scale asset purchases (LSAPs) or

2. From "Risk and Uncertainty in Monetary Policy," Chairman Greenspan's remarks at the Meeting of the American Economic Association, San Diego, California, January 3, 2004 (Greenspan 2004). 
more explicit and longer-term forward guidance about policy rates can provide considerable accommodation at the ZLB, few argue that these tools are on an equal footing with traditional policy instruments. ${ }^{3}$

One reason for this is that the effects on the economy of unconventional policies are, naturally, much more uncertain than those of traditional tools. There are divergent empirical estimates of their effects, and there is uncertainty about the theoretical mechanism behind those effects. Various studies of LSAPs, for example, provide a wide range of estimates of their ability to put downward pressure on private borrowing rates and influence the real economy. Furthermore, the effects on interest rates of both LSAPs and forward guidance are complicated functions of private-sector expectations, which make their economic effects highly uncertain as well. ${ }^{4}$

Uncertainty about the transmission mechanism of LSAPs is reflected in Arvind Krishnamurthy and Annette Vissing-Jørgensen's (2013) discussion of the various hypotheses that have been proposed. Unconventional tools also carry potential costs. The four most commonly cited costs are these: (i) the large increases in reserves generated by LSAPs risk unleashing inflation; (ii) a large balance sheet may make it more difficult for the Fed to raise interest rates when the time comes; (iii) the extended period of very low interest rates and Federal Reserve intervention in the long-term Treasury and mortgage markets may induce inefficient allocation of credit and financial fragility; and (iv) the large balance sheet puts the Federal Reserve at risk of incurring financial losses if rates rise too quickly, and such losses could undermine its support and independence. ${ }^{5}$ Costs reduce

3. For example, while there is econometric evidence that changes in term premia influence activity and inflation, some studies find that the effects appear to be less powerful than comparably sized movements in the short-term policy rate; see D'Amico and King (2015), Kiley (2012), and Chen, Curida, and Ferrero (2012).

4. Bomfin and Meyer (2010), D'Amico and King (2013), and Gagnon, Raskin, Remache, and Sack (2010) find noticeable effects of LSAPs on Treasury term premia, while Chen, Curida, and Ferrero (2012) and Hamilton and Wu (2010) unearth only small effects. Krishnamurthy and Vissing-Jørgensen (2013) argue that LSAPs only had a substantial influence on private borrowing rates in the mortgage market. Engen, Laubach, and Reifschneider (2015) and Campbell and others (2012) analyze the interactions between LSAPs' forward guidance and private sector expectations.

5. These costs are mitigated, however, by additional tools the Fed has introduced to exert control over interest rates when the time comes to exit the ZLB and by enhanced supervisory and regulatory efforts to monitor and address potential financial instability concerns. Furthermore, continued low rates of inflation and contained private-sector inflationary expectations have reduced concerns regarding an outbreak of inflation. 
the incentive to use any policy tool. Moreover, because the costs of unconventional tools are very hard to quantify, the level of uncertainty associated with them is naturally elevated as well.

A consequence of this uncertainty over the benefits and costs of unconventional tools is that they are likely to be used more cautiously than traditional policy instruments, as suggested by William Brainard's (1967) classic analysis. For example, then Federal Reserve Chairman Ben Bernanke emphasized in 2012 that because of their uncertain costs and benefits, "the hurdle for using nontraditional policies should be higher than for traditional policies." ${ }^{.6}$ In addition, some of the benefits of unconventional policies may be decreasing, and their costs may be increasing in terms of balance sheet size or amount of time spent in a very low interest rate environment. ${ }^{7}$ Accordingly, policies that had widespread support early on in a ZLB episode might be difficult to extend or expand with an already large balance sheet.

So, while they can be valuable, unconventional policies also appear to be less-than-perfect substitutes for changes in short-term policy rates. Accordingly, the ZLB presents a different set of risks to policymakers than those they face during more conventional times, and thus they are worthy of consideration in their own right. We abstract from unconventional policy tools for the remainder of our analysis.

\section{Rationales for Risk Management Near the ZLB}

The canonical framework of monetary policy analysis assumes that the central bank sets the nominal interest rate to minimize a quadratic loss function of the deviation of inflation from its target and the output gap, and that the economy is described by a set of linear equations. In most applications, uncertainty is incorporated as additive shocks to these linear equations, capturing factors outside the model that lead to variation in economic activity

6. "Monetary Policy since the Onset of the Crisis," Remarks by Chairman Ben S. Bernanke at the Federal Reserve Bank of Kansas City Economic Symposium, Jackson Hole, Wyoming, August 31, 2012 (Bernanke 2012, p. 14).

7. Krishnamurthy and Vissing-Jørgensen (2013) argue successive LSAP programs have had a diminishing influence on term premia. Surveys conducted by Blue Chip and the Federal Reserve Bank of New York also indicate that market participants are less optimistic that further asset purchases would provide much stimulus if the Fed were forced to expand their use in light of unexpected economic weakness. 
or inflation. ${ }^{8}$ A limitation of this approach is that, by construction, it denies that a policymaker might choose to adjust policy in the face of changes in uncertainty about economic fundamentals. However, the evidence discussed below in sections II and III suggests that in practice, policymakers are sensitive to uncertainty and respond to it by following what appears to be a risk-management approach. Understanding why a central banker should behave in this way requires some departure from the canonical framework. The main contribution of this section is to consider a departure associated with the possibility of a binding ZLB in the future. We show that when a policymaker might be constrained by the ZLB in the future, optimal policy today should take account of uncertainty about fundamentals. We focus on two distinct channels through which this can occur. First, we use the workhorse forward-looking New Keynesian model to illustrate the expectations channel, in which the possibility of a binding ZLB tomorrow leads to lower expected inflation and an output gap occurring today, thus necessitating policy easing today. We then use a backward-looking "Old" Keynesian setup to illustrate the buffer stock channel, in which it can be optimal to build up output or inflation today in order to reduce the likelihood and severity of being constrained by the ZLB tomorrow. Both of these channels operate in modern DSGE (dynamic stochastic general equilibrium) models such as those described by Lawrence Christiano, Martin Eichenbaum, and Charles Evans (2005) and by Frank Smets and Rafael Wouters (2007), but they are more transparent if we consider them in separate, although related, simple models. After describing these two channels we construct some numerical simulations to assess their quantitative effects.

\section{I.A. The Expectations Channel}

The simple New Keynesian model has well established micro-foundations based on price stickiness. Given that excellent expositions of these foundations have been offered many times, for example by Michael Woodford (2003) and Jordi Galí (2008), we simply state our notation without much explanation. The model consists of two main equations, the Phillips curve and the IS curve.

The Phillips curve is specified as

$$
\pi_{t}=\kappa x_{t}+\beta E_{t} \pi_{t+1}+u_{t},
$$

8. This framework can be derived from a micro-founded DSGE model (see for instance Woodford [2003], Chapter 6), but it has a longer history and is used even in models that are not fully micro-founded. The Federal Reserve Board staff routinely conducts optimal policy exercises in the FRB/US model; see for example English, Lopez-Salido, and Tetlow (2013). 
where $\pi_{t}$ and $x_{t}$ are both endogenous variables and denote inflation and the output gap at date $t ; E_{t}$ is the date $t$ conditional expectations operator with rational expectations is assumed; $u_{t}$ is a mean zero exogenous cost-push shock; and $0<\beta<1, \kappa>0$. For simplicity we assume the central bank has a constant inflation target equal to zero, so $\pi_{t}$ is the deviation of inflation from that target. The cost-push shock represents exogenous changes to inflation such as an independent decline in inflation expectations, dollar appreciation, or changes in oil prices.

The IS curve is specified as

$$
x_{t}=E_{t} x_{t+1}-\frac{1}{\sigma}\left(i_{t}-E_{t} \pi_{t+1}-\rho_{t}^{n}\right),
$$

where $\sigma>0, i_{t}$ is the nominal interest rate controlled by the central bank, and $\rho_{t}^{n}$ is the natural rate of interest given by

$$
\rho_{t}^{n}=\bar{\rho}+\sigma g_{t}+\sigma E_{t}\left(z_{t+1}-z_{t}\right) .
$$

The variable $g_{t}$ is an exogenous mean zero demand shock, and $z_{t}$ is the exogenous $\log$ of potential output. Since $g_{t}$ and $z_{t}$ are exogenous, so is the natural rate. Equation 2 indicates that $\rho_{t}^{n}$ corresponds to the setting of the nominal interest rate consistent with expected inflation at target and the output gap equal to zero. ${ }^{9}$ If potential output is constant and the demand shock equals zero, then the natural rate equals the constant $\bar{\rho}>0$.

Our analysis is centered on uncertainty in the natural rate. ${ }^{10}$ From equation 3 we see that this uncertainty derives from uncertainty about $g_{t}$ and $E_{t}\left(z_{t+1}-z_{t}\right)$. We interpret the former as arising due to a variety of factors, including fiscal policy, foreign economies' growth, and financial considerations such as deleveraging. ${ }^{11}$ The latter source of uncertainty is over the variety of factors that can influence the expected rate of growth in potential

9. Woodford (2003, p. 248) defines the natural rate as the equilibrium real rate of return in the case of fully flexible prices. As discussed by Barsky, Justiniano, and Melosi (2014), in medium-scale DSGE models with many shocks the appropriate definition of the natural rate is less clear.

10. There is ample evidence of considerable uncertainty regarding the natural rate. See for example Barsky, Justiniano, and Melosi (2014), Hamilton and others (2015), and Laubach and Williams (2003).

11. Uncertainty itself could give rise to $g_{t}$ shocks. A large amount of recent work, following Bloom (2009), suggests that private agents react to increases in economic uncertainty, leading to a decline in economic activity. One channel is that higher uncertainty may lead to precautionary savings, which in turn depresses demand, as is emphasized by Basu and Bundick (2014), Fernandez-Villaverde and others (2012), and Born and Pfeifer (2014). 
output, for example as emphasized in the recent debate over so-called secular stagnation.

We adopt the canonical framework in assuming that the central bank acts to minimize a quadratic loss function with the understanding that privatesector behavior is governed by equations 1 through 3 . The loss function is

$$
L=\frac{1}{2} E_{0} \sum_{t=0}^{\infty} \beta^{t}\left(\pi_{t}^{2}+\lambda x_{t}^{2}\right),
$$

where $\lambda \geq 0$. We further assume the ZLB constraint, that is, $i_{t} \geq 0$, abstracting from the possibility that the effective lower bound on $i_{t}$ is slightly negative. The short-term interest rate is the central bank's only policy instrument, and it is set by solving for optimal policy under discretion. In particular, in each period the central bank sets the nominal interest rate with the understanding that private agents anticipate that it will re-optimize in the following periods.

We focus on optimal policy under discretion for two reasons. First, the case of commitment with a binding ZLB already has been studied extensively. In particular, it is well known from the contributions of Paul Krugman (1998), Gauti Egertsson and Michael Woodford (2003), Woodford (2012), and Iván Werning (2012) that commitment can reduce the severity of the ZLB problem by creating higher expectations of inflation and the output gap. One implication of these studies is that the central bank should commit to keeping the policy rate at zero longer than would be prescribed by discretionary policy. By studying optimal policy under discretion we find a different rationale for a policy of keeping rates "lower for longer" that does not rely on the central bank having the ability to commit to a time-inconsistent policy. ${ }^{12}$ Nevertheless, below we discuss our intuition for why our main result should extend to the case of commitment. Second, discretion may better approximate the institutional environment in which the FOMC operates.

A ZLB SCENARIO We study optimal policy when the central bank is faced with the following simple ZLB scenario. The central bank observes the current value of the natural rate, $\rho_{0}^{n}$, and the cost-push shock $u_{0}$;

12. Implicitly we are assuming the central bank does not have the ability to employ what Campbell and others (2012) call "Odyssean" forward guidance. However, our model is consistent with the central bank's using forward guidance in the "Delphic" sense they describe because agents anticipate how the central bank reacts to evolving economic conditions. 
moreover, there is no uncertainty in the natural rate after $t=2, \rho_{t}^{n}=\bar{\rho}>0$ for all $t \geq 2$, nor in the cost-push shock after $t=1, u_{t}=0$ for all $t \geq 1$. However, there is uncertainty at $t=1$ regarding the natural rate $\rho_{1}^{n} \cdot{ }^{13}$ The variable $\rho_{1}^{n}$ is assumed to be distributed according to the probability density function $f_{\mathrm{\rho}}(\cdot)$.

This very simple scenario keeps the optimal policy calculation tractable while preserving the main insights. We also think it captures some key elements of uncertainty faced by the FOMC today; notably, our formulation allows us to consider the optimal timing of liftoff. We do not have to take a stand on whether the ZLB is binding before $t=0$, but one possibility is that the natural rate $\rho_{t}^{n}$ was sufficiently negative for $t<0$ so that the optimal policy rate was set at zero, $i_{t}=0$ for $t<0$, but because the economy has been improving the natural rate is close to zero by $t=0$. The question is whether to raise the policy rate at $t=0, t=1$, or $t=2$.

ANALYSIS To find the optimal policy, we solve the model backwards from $t=2$ and focus on the policy choice at $t=0$. First, for $t \geq 2$, it is possible to perfectly stabilize the economy by setting the nominal interest rate equal to the (now positive) natural rate, $i_{t}=\rho_{t}^{n}=\bar{\rho}$. This leads to $\pi_{t}=x_{t}=0$ for $t \geq 2 .{ }^{14}$ The optimal policy at $t=1$ will depend on the realized value of the natural rate $\rho_{1}^{n}$. If $\rho_{1}^{n} \geq 0$, then it is again possible (and optimal) to perfectly stabilize by setting $i_{1}=\rho_{1}^{n}$, leading to $x_{1}=\pi_{1}=0$. However if $\rho_{1}^{n}<0$, the ZLB binds and consequently $x_{1}=\rho_{1}^{n} / \sigma<0$. The expected output gap at $t=1$ is $E_{0} x_{1}=\int_{-\infty}^{0} \rho f_{\rho}(\rho) d \rho / \sigma \leq 0$ and expected inflation is $E_{0} \pi_{1}=\kappa E_{0} x_{1}<0$.

Because agents are forward-looking, this low expected output gap and inflation feed backward to $t=0$. A low output gap tomorrow depresses output today by a wealth effect via the IS curve. Low inflation tomorrow depresses inflation today, since price-setting is forward-looking in the Phillips curve, and it also depresses output today by raising the real interest rate via the IS curve. The optimal policy at $t=0$ must take into account these effects. This implies that optimal policy will be looser than if there were no chance that the ZLB would bind tomorrow.

13. It is easy to verify that if the uncertainty about the natural rate is only at $t=0$ the optimal policy would be to set the interest rate to the expected value of the natural rate, and the amount of uncertainty would have no effect. This is why our scenario has more than two periods.

14. This simple interest rate rule implements the equilibrium $\pi_{t}=x_{t}=0$ but is also consistent with other equilibria. However, there are standard ways to rule out these other equilibria. See Galí (2008, pp. 76-77) for a discussion. Henceforth we will not consider this issue. 
Mathematically, substituting for $\pi_{0}$ and $i_{0}$ using equations 1 and 2 , and taking into account the ZLB constraint, optimal policy at $t=0$ solves the following problem:

$$
\min _{x_{0}} \frac{1}{2}\left[\left(\kappa x_{0}+\beta E_{0} \pi_{1}+u_{0}\right)^{2}+\lambda x_{0}^{2}\right] \text { s.t. } x_{0} \leq E_{0} x_{1}+\frac{1}{\sigma}\left(\rho_{0}^{n}+E_{0} \pi_{1}\right) .
$$

Two cases arise, depending on whether the ZLB binds at $t=0$ or not. Define the threshold value

$$
\rho_{0}^{*}=-\sigma \frac{\kappa}{\lambda+\kappa^{2}} u_{0}-\left(1+\frac{\kappa}{\sigma}+\beta \frac{\kappa^{2}}{\lambda+\kappa^{2}}\right) \int_{-\infty}^{0} \rho f_{\rho}(\rho) d \rho
$$

If $\rho_{0}^{n}>\rho_{0}^{*}$, then the optimal policy is to follow the standard monetary policy response to an inflation shock to the Phillips curve, $\beta E_{0} \pi_{1}+u_{0}$, leading to

$$
x_{0}=-\frac{\kappa}{\lambda+\kappa^{2}}\left(\beta E_{0} \pi_{1}+u_{0}\right) ; \quad \pi_{0}=\frac{\lambda}{\lambda+\kappa^{2}}\left(\beta E_{0} \pi_{1}+u_{0}\right) .
$$

The corresponding interest rate is

$$
\begin{aligned}
i_{0} & =\rho_{0}^{n}+E_{0} \pi_{1}+\sigma\left(E_{0} x_{1}-x_{0}\right) \\
& =\rho_{0}^{n}+\sigma \frac{\kappa}{\lambda+\kappa^{2}} u_{0}+\left(1+\frac{\kappa}{\sigma}+\beta \frac{\kappa^{2}}{\lambda+\kappa^{2}}\right) \int_{-\infty}^{0} \rho f_{\rho}(\rho) d \rho .
\end{aligned}
$$

As long as $\int_{-\infty}^{0} \rho f_{\rho}(\rho) d \rho<0$, equation 8 implies that the optimal interest rate is lower than if there were no chance of a binding ZLB tomorrow, that is, if $f_{\rho}(\rho)=0$ for $\rho \leq 0$. The interest rate is lower today to offset the deflationary and recessionary effects of the possibility of a binding ZLB tomorrow. If $\rho_{0}^{n}<\rho_{0}^{*}$, then the ZLB binds today and optimal policy is $i_{0}=0$. In this case,

$$
x_{0}=\frac{\rho_{0}^{n}}{\sigma}+\left(1+\frac{\kappa}{\sigma}\right) E_{0} x_{1} ; \quad \pi_{0}=\kappa \frac{\rho_{0}^{n}}{\sigma}+\left[(1+\beta) \kappa+\frac{\kappa^{2}}{\sigma}\right] E_{0} x_{1} .
$$

Notice from equation 6 that higher uncertainty makes it more likely that the ZLB will bind at $t=0$. Specifically, even if agents were certain that the ZLB would not bind at $t=1, E_{0} x_{1}=E_{0} \pi_{1}=0$ and $i_{0}=0$ if $\rho_{0}^{n} \leq-\sigma \kappa u_{0} /\left(\lambda+\kappa^{2}\right)$. 
So the possibility of the ZLB binding tomorrow increases the chances of being constrained by the ZLB today.

Since $E_{0} x_{1}$ is a sufficient statistic for $\int_{-\infty}^{0} \rho f_{\rho}(\rho) d \rho$ in equation 8 , the optimal policy has the flavor of a traditional forward-looking policy reaction function that only depends on the conditional expectations of output and inflation gaps. However $E_{0} x_{1}$ is not independent of a mean-preserving spread or any other change in the distribution of $\rho_{1}^{n}$. Accordingly, optimal policy here departs from the certainty equivalence principle, which says that the extent of uncertainty in the underlying fundamentals (in our case $\rho_{1}^{n}$ ) does not affect the optimal interest rate ${ }^{15}$ Furthermore, as a practical matter the central bank must infer private agents' $E_{0} x_{1}$ in order to determine optimal policy. Since $E_{0} x_{1}$ depends on the entire distribution of $\rho_{1}^{n}$, so must the central bank's estimates of it, which is a much more difficult inference problem than in the certainty equivalence case.

Turning specifically to the issue of uncertainty, we obtain the following unambiguous comparative static result:

Proposition 1: Higher uncertainty, that is, a mean-preserving spread in the distribution of the natural rate $\rho_{1}^{n}$ tomorrow, leads to a looser optimal policy today.

To see this, rewrite the key quantity $\int_{-\infty}^{0} \rho f_{\rho}(\rho) d \rho=E \min (\rho, 0)$. Since the min function is concave, higher uncertainty through a mean-preserving spread about $\rho_{1}^{n}$ leads to lower, that is, more negative, $E_{0} x_{1}$ and $E_{0} \pi_{1}$. Hence, higher uncertainty leads to lower $i_{0}{ }^{16}$

The effect of higher uncertainty on $i_{0}$ is unambiguous, but the effect on the output gap and inflation is more subtle. If the ZLB does not bind at $t=0$ initially, higher uncertainty leads to lower $E_{0} x_{1}$ and $E_{0} \pi_{1}$ and consequently to higher $x_{0}$ and lower $\pi_{0}$ according to equation 7 . On the other hand, if the ZLB does bind at $t=0$ initially, then higher uncertainty leads to lower $x_{0}$ and lower $\pi_{0}$ according to equation $9 .{ }^{17}$ Overall, the effect of higher uncertainty on $\pi_{0}$ is unambiguously negative, but the effect on $x_{0}$ may be positive or negative.

15. Recent statements of the certainty equivalence principle in models with forwardlooking variables can be found in Svensson and Woodford (2002, 2003).

16. See Mas-Colell, Whinston, and Green (1995, Proposition 6.D.2, p. 199) for the relevant result regarding the effect of a mean-preserving spread on the expected value of concave functions of a random variable.

17. Finally, there is a case where the ZLB does not bind initially but does bind if uncertainty is higher. In this case, $x_{0}$ may be lower or higher with higher uncertainty, while $\pi_{0}$ is always smaller. 
Another interesting feature of the solution is that the distribution of the positive values of $\rho_{1}^{n}$ is irrelevant for policy. That is, policy today is adjusted only with respect to the states of the world in which the ZLB might bind tomorrow. The logic is that if a very high value of $\rho_{1}^{n}$ is realized, monetary policy can adjust to it and prevent a bout of inflation. This is a consequence of the standard principle that, outside the ZLB, natural rate shocks can and should be perfectly offset by monetary policy.

DISCUSSION Proposition 1 has several predecessors. Perhaps the closest are Klaus Adam and Roberto Billi (2007), Taisuke Nakata (2013a,b), and Anton Nakov (2008), who demonstrate numerically how, in a stochastic environment, the ZLB leads the central bank to adopt a looser policy. Our contribution is to provide a simple analytical example. ${ }^{18}$ This result has been correctly interpreted to mean that if negative shocks to the natural rate lead the economy to be close to the ZLB, the optimal response is to lower the interest rate aggressively to reduce the likelihood that the ZLB becomes binding. The same logic applies to liftoff. Following an episode where the ZLB has been a binding constraint, the central bank should not raise rates as if it were sure the ZLB constraint would never bind again. ${ }^{19}$ Even though the best forecast may be that the economy will recover and exit the ZLB - that is, in the context of the model, that $E_{0}\left(\rho_{1}^{n}\right)>0$ - it can be optimal to have zero interest rates today. Note that policy is looser when the probability of being constrained by the ZLB in the future is high or the potential severity of the ZLB problem is large; that is, when $\int_{-\infty}^{0} \rho f_{\rho}(\rho) d \rho$ is a large negative number; the economy is less sensitive to interest rates (high $\sigma$ ); and the Phillips curve is steep (high $\kappa$ ).

With higher uncertainty, the increase in interest rates will be faster on average from $t=0$ to $t=2$. This follows since the $t=2$ interest rate is unaffected by uncertainty whereas at $t=0$ it is lower. More generally, when uncertainty about being constrained by the ZLB in the future dissipates, the interest rate can rise quickly because the effects holding it down disappear along with the uncertainty.

While we have deliberately focused on a very simple example, our results hold under more general conditions. For instance, the same results still hold if $\left\{\rho_{t}^{n}\right\}_{\not \geq 2}$ follows an arbitrary stochastic process, as long as it is positive. In the online appendix we consider the case of optimal policy

18. See also Nakata and Schmidt (2014) for a related analytical result in a model with two-state Markov shocks.

19. Indeed, private sector forecasters attribute a significant likelihood of a return to the ZLB: respondents to the January 2015 Federal Reserve Bank of New York survey of Primary Dealers put the odds of returning to the ZLB within two years following liftoff at 20 percent. 
with uncertainty about cost-push inflation..$^{20}$ We show that optimal policy also is looser if there is a chance of a binding ZLB in the future due to a low cost-push shock. Furthermore, the risk that inflation picks up due to a high cost-push shock does not affect policy today. If such a shock were to occur tomorrow, it would lead to some inflation; however, there is nothing that policy today can do about it. Finally, while the model chosen is highly stylized, the core insights would likely continue to hold in a medium-scale model with a variety of shocks and frictions.

Intuitively, we expect a version of Proposition 1 to still hold with commitment as well. Optimal policy with commitment involves promising at $t=0$ that should the ZLB bind at $t=1$, the central bank would keep interest rates lower for $t \geq 2$ than it would otherwise. As is well known, this policy reduces the size of the inflation and output gaps at $t=1$, but it does not eliminate them entirely. These gaps then could generate negative expected inflation and output gaps at $t=0$ that become more negative the larger the $t=1$ uncertainty. Higher uncertainty should therefore lead to looser policy at $t=0$, just as in the case of discretion.

One obvious limitation to these results is that we have assumed (and will continue do so when studying the backward-looking model below) that there is no cost to raising rates quickly if needed. For example, our welfare criterion does not value interest-rate smoothing. Smoothing has been rationalized by Marvin Goodfriend (1991) and others as facilitating financial market adjustments or as a signaling tool. It is true also that estimated reaction functions include lagged funds rate terms to fit historical data. Nonetheless, there have been instances when the FOMC has moved quickly. Some of these occurred as recessions unfolded, but not all: between February 1994 and February 1995 rates were tightened by 300 basis points and between November 1988 and February 1989 by nearly 165 basis points. Moreover, as Brian Sack (2000) and Glenn Rudebusch (2002) argue, interest rate smoothing might reflect learning about an uncertain economy rather than a desire to avoid large changes in interest rates per se. The policy prescriptions derived from our models are specifically aimed at addressing such uncertainty.

\section{I.B. The Buffer Stock Channel}

The buffer stock channel relies not on forward-looking behavior but on the view that the economy has some inherent momentum, for instance due

20. Online appendixes to all papers in this volume may be found at the BPEA web page, www.brookings.edu/bpea, under "Past Editions." 
to adaptive inflation expectations, inflation indexation, habit persistence, adjustment costs, or hysteresis. Suppose that output or inflation has a tendency to persist. If there is a risk that the ZLB binds tomorrow, building up output and inflation today creates some buffer against hitting the ZLB tomorrow.

This intuition does not guarantee that it is optimal to increase output or inflation today. In particular, the benefit of higher inflation or output today in the event that a ZLB event arises tomorrow must be weighed against the costs of excess output and inflation today, as well as tomorrow's cost to bring down the output gap or inflation if the ZLB turns out not to bind. So it is important to verify that our intuition holds up in a model.

To isolate the buffer stock channel from the expectations channel we focus on a purely backward-looking "Old" Keynesian model. Purely backwardlooking models do not have micro-foundations as the New Keynesian model does, but backward-looking elements appear to be important empirically. ${ }^{21}$ Backward-looking models have been studied extensively in the literature, including by Thomas Laubach and John Williams (2003), Athanasios Orphanides and Williams (2002), David Reifschneider and Williams (2000), and Rudebusch and Lars Svensson (1999).

The model we study simply replaces the forward-looking terms in equations 1 and 2 with backward-looking terms:

$$
\begin{gathered}
\pi_{t}=\xi \pi_{t-1}+\kappa x_{t}+u_{t} ; \\
x_{t}=\delta x_{t-1}-\frac{1}{\sigma}\left(i_{t}-\rho_{t}^{n}-\pi_{t-1}\right),
\end{gathered}
$$

where $0<\xi<1$ and $0<\delta<1$. This model is essentially the same as the simple example Reifschneider and Williams (2000) use to motivate their analysis of monetary policy constrained by the ZLB. Unlike in the New Keynesian model, it is difficult to map $\rho_{t}^{n}$ directly to underlying fundamental shocks as we do in equation 3. For simplicity, we continue to refer to this exogenous variable as the natural rate and use equation 3 as a guide to

21. Indeed, empirical studies based on medium-scale DSGE models, such as those considered by Christiano, Eichenbaum, and Evans (2005) and Smets and Wouters (2007), find that backward-looking elements are essential to account for the empirical dynamics. Backward-looking terms are important in single-equation estimation as well. See for example Fuhrer (2000), Galí and Gertler (1999), and Eichenbaum and Fisher (2007). 
interpreting it, but it is perhaps better to think of it as simply a "demand" shock or "IS" shock.

ANALYSIS We consider the ZLB scenario described in section I.A (under "A ZLB Scenario") and again solve the model backwards from $t=2$ to determine optimal policy at $t=0$ and how this is affected by uncertainty in the natural rate at $t=1$. After $t=1$ the economy does not experience any more shocks, but it inherits initial lagged inflation and output terms $\pi_{1}$ and $x_{1}$, which may be positive or negative. The output gap term can be easily adjusted by changing the interest rate $i_{t}$ provided the central bank is not constrained by the ZLB at $t=2$, that is, if $\rho_{2}^{n}=\bar{\rho}$ is large enough, an assumption we will maintain. ${ }^{22}$ Given the quadratic loss, it is optimal to smooth this adjustment over time so that the economy will converge back to its steady-state slowly. The details of this adjustment after $t=2$ are not very important for our analysis. What is important is that the overall loss of starting from $t=2$ with lagged inflation $\pi_{1}$ and output gap $x_{1}$ is a quadratic function of $\pi_{1}$ only; we can write it as $W \pi_{1}^{2} / 2$, where $W$ is a constant that depends on $\lambda, \kappa, \xi$, and $\beta$ and is calculated in the online appendix.

Turn now to optimal policy at $t=1$. Take the realization of $\rho_{1}^{n}$ and last period's output gap $x_{0}$ and inflation $\pi_{0}$ as given. Substituting for $\pi_{1}$ and $i_{1}$ using equations 10 and 11 , and taking into account the ZLB constraint, optimal policy at $t=1$ solves the following problem:

$$
V\left(x_{0}, \pi_{0}, \rho_{1}^{n}\right)=\min _{x_{1}} \frac{1}{2}\left[\left(\xi \pi_{0}+\kappa x_{1}\right)^{2}+\lambda x_{1}^{2}\right]+\beta \frac{W}{2} \pi_{1}^{2} \text { s.t. } x_{1} \leq \delta x_{0}+\frac{\pi_{0}+\rho_{1}^{n}}{\sigma},
$$

where the policymaker now anticipates the cost of having inflation $\pi_{1}$ tomorrow, and her choices are affected by yesterday's values $x_{0}$ and $\pi_{0}$.

Depending on the value of $\rho_{1}^{n}$, two cases can arise. Define the threshold value:

$$
\rho_{1}^{*}\left(x_{0}, \pi_{0}\right)=-\left[\frac{(1+\beta W) \kappa \xi}{(1+\beta W) \kappa^{2}+\lambda} \sigma+1\right] \pi_{0}-\sigma \delta x_{0} .
$$

For $\rho_{1}^{n} \geq \rho_{1}^{*}\left(x_{0}, \pi_{0}\right)$ the ZLB is not binding; otherwise it is. Hence the probability of hitting the ZLB is $\int_{-\infty}^{\rho_{i}\left(x_{0}, \pi_{0}\right)} f_{\rho}(\rho) d \rho$. In contrast to the forwardlooking case, the probability of being constrained by the ZLB constraint is now endogenous at $t=1$ and can be influenced by policy at $t=0$. As

22. Relaxing it would only strengthen our results. 
indicated by equation 12 , a higher output gap or inflation at $t=0$ will reduce the likelihood of hitting the ZLB at $t=1$.

If $\rho_{1}^{n} \geq \rho_{1}^{*}\left(x_{0}, \pi_{0}\right)$ optimal policy at $t=1$ yields

$$
x_{1}=-\frac{(1+\beta W) \kappa \xi}{(1+\beta W) \kappa^{2}+\lambda} \pi_{0} ; \quad \pi_{1}=\frac{\lambda \xi}{(1+\beta W) \kappa^{2}+\lambda} \pi_{0} .
$$

This is similar to the forward-looking model's solution, which reflects the trade-off between output and inflation, except that optimal policy now takes into account the cost of having inflation away from target tomorrow, through $W$. The loss for this case is $V\left(x_{0}, \pi_{0}, \rho_{1}^{n}\right)=W \pi_{0}^{2} / 2$, since in this case the problem is the same as the one faced at $t=2$. If $\rho_{1}^{n}<\rho^{*}\left(x_{0}, \pi_{0}\right)$ the ZLB binds, in which case

$$
x_{1}=\delta x_{0}+\frac{\pi_{0}+\rho_{1}^{n}}{\sigma} ; \quad \pi_{1}=\kappa \delta x_{0}+\pi_{0}\left(\xi+\frac{\kappa}{\sigma}\right)+\kappa \frac{\rho_{1}^{n}}{\sigma} .
$$

The expected loss from $t=1$ on as a function of the output gap and inflation at $t=0$ is then given by:

$$
\begin{aligned}
L\left(x_{0}, \pi_{0}\right)= & \frac{W}{2} \pi_{0}^{2} \int_{\rho_{1}^{*}\left(x_{0}, \pi_{0}\right)}^{+\infty} f_{\rho}(\rho) d \rho+ \\
& \int_{-\infty}^{\rho_{1}^{*}\left(x_{0}, \pi_{0}\right)} \frac{1+\beta W}{2}\left[\kappa \delta x_{0}+\pi_{0}\left(\xi+\frac{\kappa}{\sigma}\right)+\kappa \frac{\rho}{\sigma}\right]^{2}+ \\
& \frac{\lambda}{2}\left(\delta x_{0}+\frac{\pi_{0}+\rho}{\sigma}\right)^{2} f_{\rho}(\rho) d \rho .
\end{aligned}
$$

This expression reveals that the initial conditions $x_{0}$ and $\pi_{0}$ matter by shifting the payoff from continuation in the non-ZLB states, $W \pi_{0}^{2} / 2$; the payoff in the case where the ZLB binds (the second integral); and the relative likelihood of ZLB and non-ZLB states through $\rho_{1}^{*}\left(x_{0}, \pi_{0}\right)$. Since the loss function is continuous in $\rho$, even at $\rho_{1}^{*}\left(x_{0}, \pi_{0}\right)$, this last effect is irrelevant for welfare at the margin.

The last step is to find the optimal policy at time 0 , taking into account the effect on the expected loss tomorrow:

$$
\min _{x_{0}} \frac{1}{2}\left[\left(\xi \pi_{-1}+\kappa x_{0}+u_{0}\right)^{2}+\lambda x_{0}^{2}\right]+\beta L\left(x_{0}, \pi_{0}\right) \text { s.t. } x_{0} \leq \delta x_{-1}+\frac{\rho_{0}^{n}+\pi_{-1}}{\sigma} .
$$


We use this expression to prove the following, which is analogous to Proposition 1:

Proposition 2: For any initial condition, a mean-preserving spread in the distribution of the natural rate $\rho_{1}^{n}$ tomorrow leads to a looser optimal policy today.

From equations 10 and 11, higher uncertainty also leads to larger $x_{0}$ and $\pi_{0}$. The proof of Proposition 2 is in the appendix. Note that it incorporates the case of uncertainty regarding cost-push shocks at $t=1$ and shows that a mean-preserving spread in the cost-push shock tomorrow leads to looser policy today as well.

Our model also implies that an increase in uncertainty over the initial output gap will lead to looser policy. Specifically we have:

Proposition 3: Suppose the initial output gap $x_{-1}$ is unknown at $t=0$ but becomes known at $t=1$ and the central bank has a prior distribution over $x_{-1}$. Then a mean-preserving spread in this prior distribution leads optimal policy to be looser at $t=0$.

The proof of this proposition is similar to the one for Proposition 2. This result is particularly germane to the current policy environment where there is uncertainty over the amount of slack in the economy. Therefore, Proposition 3 provides an additional rationale for delaying liftoff.

DISCUSSION As far as we know, Proposition 2 is a new result, but its implications are similar to those of Proposition 1. As in the forwardlooking case, liftoff from an optimal zero interest rate should be delayed today with an increase in uncertainty about the natural rate or cost-push shock that raises the odds of the ZLB binding tomorrow. Similarly, even if not constrained by the ZLB today, an increase in uncertainty about the likelihood of being constrained by the ZLB tomorrow leads to a reduction in the policy rate today. So the buffer stock channel and the expectations channel have very similar policy implications, though for very different reasons. The expectations channel involves the possibility of being constrained by the ZLB tomorrow feeding backward to looser policy today. The buffer stock channel has looser policy today feeding forward to reduce the likelihood and severity of being at the ZLB tomorrow. Note that as in the forward-looking model, optimal policy prescribes that interest rates rise as the likelihood of being constrained by the ZLB in the future falls, even if the output gap or inflation does not change.

It is useful to compare the policy implications of the buffer stock channel to the argument developed in Olivier Coibion, Yuriy Gorodnichenko, and 
Johannes Wieland (2012). Their paper studies the tradeoff between the level of the inflation target and the risk of hitting the ZLB using policy reaction functions instead of optimal policy. ${ }^{23}$ Our analysis does not require a drastic change in monetary policy in order to improve outcomes. It is achieved through standard interest-rate policy rather than a credibilitydamaging change to the inflation target.

\section{I.C. Quantitative Assessment}

We now assess the quantitative significance of the expectations and buffer stock channels using calibrated versions of the forward- and backwardlooking models that we solve numerically. With parameters drawn from the literature and initial conditions calibrated to early 2015, we compare equilibrium outcomes under optimal discretion to alternative policies that do not take into account uncertainty. Our numerical methods are described in the online appendix. Importantly, and in contrast to most of the literature, they allow uncertainty to affect policy and to be reflected in welfare.

PARAMETER VALUES The parameter values are reported in table 1 . We use the same values for parameters that are common to both models. The time period is one quarter, with $t=1$ taken to be 2015Q1. The natural rate $\rho_{t}^{n}$ is the sum of deterministic and random components. We assume the deterministic component rises linearly between $t=1$ and $t=T>1$, after which it remains constant at $\bar{\rho}=1.75$ percent, which corresponds with the median long-run funds rate in the March 2015 FOMC Summary of Economic Projections, less the FOMC's inflation target $\pi^{*}=2$. The random component is $\mathrm{AR}(1)$ with auto-correlation coefficient $\rho_{\varepsilon}$ and innovation standard deviation $\sigma_{\varepsilon}$. We also assume there is an i.i.d. cost-push shock with standard deviation $\sigma_{u}$. There is no uncertainty for $t>T$.

The degree of uncertainty we assume is central to our findings. The particular values of $\rho_{\varepsilon}$ and $\sigma_{\varepsilon}$ are not as important to our results as the unconditional volatility they imply. There is wide variation in estimates of volatility in the natural rate, corresponding to differences in theoretical concepts, models and empirical methods used. Our calibration implies that the unconditional standard deviation of the natural rate is 2.5 percent at an annual rate. This lies within the range of estimates in Robert Barsky, Alejandro Justiniano, and Leonardo Melosi (2014), Vasco Cúrdia and others (2015), and Laubach and Williams (2003). The auto-correlation

23. Another difference is that they study a medium-scale DSGE model with both forward- and backward-looking elements; because of this added complexity, they use a different solution method. 
Table 1. Parameter Values ${ }^{\mathrm{a}}$

\begin{tabular}{llc}
\hline Parameter & \multicolumn{1}{c}{ Description } & Value \\
\hline$\beta$ & Discount factor & 0.995 \\
$\kappa$ & Slope of Phillips curve & 0.025 \\
$\sigma$ & Inverse elasticity of substitution & 2 \\
$\sigma_{\varepsilon}$ & Standard deviation natural rate innovation & 1.32 \\
$\sigma_{u}$ & Standard deviation of cost-push innovation & 0.10 \\
$\rho_{\varepsilon}$ & Serial correlation of natural rate & 0.85 \\
$\rho_{u}$ & Serial correlation of cost-push & 0 \\
$\lambda$ & Weight on output stabilization & 0.25 \\
$\pi^{*}$ & Steady-state inflation (annualized) & 2 \\
$\rho_{i}^{n}$ & Value of natural rate at time 1 & -0.5 \\
$T$ & Quarters to reach terminal natural rate & 24 \\
$\bar{\rho}$ & Terminal natural rate (annualized) & 1.75 \\
$\delta$ & Backward-looking IS curve coefficient & 0.75 \\
$\xi$ & Backward-looking Phillips curve coefficient & 0.95 \\
$x_{0}$ & Initial condition for the output gap & -1.5 \\
$\pi_{0}$ & Initial condition for inflation & 1.3 \\
$\varphi$ & Taylor rule coefficient on inflation & 1.5 \\
$\gamma$ & Taylor rule coefficient on output gap & 0.5 \\
\hline
\end{tabular}

Source: Authors' calculations.

a. Values of standard deviations, inflation, the output gap, and the natural rate are shown in percentage points.

coefficient is set midway between the values in Adam and Billi (2007) and Cúrdia and others (2015). We set the standard deviation of the cost-push shock $\sigma_{u}$ close to the value used in Adam and Billi (2007). Assuming serial correlation or a moderately different unconditional standard deviation of the cost-push shock is not very important for our results. Finally, by assuming that the economy is not subject to shocks for $t>T$ and that the long run natural rate $\bar{\rho}$ is a known constant, we have been conservative in our specification of uncertainty.

The Phillips curve slope, elasticity of intertemporal substitution, and discount factor are all set to values common in the New Keynesian literature. For the backward-looking model we set the coefficient on lagged inflation in equation 10 to $\xi=0.95$, reflecting the fact that inflation has been very persistent in recent years. ${ }^{24}$ The coefficient on lagged output in equation 11 is $\delta=0.75$, in order to generate significant persistence in the output gap. For the backward-looking model we assume an initial inflation rate of 1.3 percent, a recent reading for core PCE inflation, and an

24. Note that it is not clear how to map estimates of the lagged inflation coefficient in the literature to our backward-looking model since these are based on Phillips curves with forward-looking terms. 
initial output gap $x_{0}=-1.5$ percent, based on a simple calculation using the 2014Q4 unemployment rate (5.7 percent), an estimate of the natural rate of unemployment (5.0 percent), and Okun's law. As indicated by Proposition 3, adding uncertainty about the initial output gap would only strengthen our results. $^{25}$

We measure the quantitative effect of uncertainty on policy by comparing equilibrium outcomes under optimal discretion to a scenario in which we solve for optimal discretion when the central bank observes the current natural rate and cost-push shocks but acts as if there will be no more shocks. Private agents understand this policy but take into account the true nature of uncertainty. Actual outcomes will be inconsistent with the central bank's assumptions, so we call this the "naive" policy. We also compare equilibrium outcomes under optimal discretion to those obtained assuming the central bank follows a reaction function with weights on inflation and the output gap as in John Taylor (1993), and a constant term equal to 3.75 percent corresponding to $\rho+\pi *$.

RESULTS FOR THE FORWARD-LOOKING MODEL Figure 1 displays representative paths of the nominal interest rate, inflation, and the output gap under optimal discretion, the naive policy, and the Taylor rule, calculated by setting the ex post realized shocks to zero, the modal outcome. Under the modal outcome, the interest rate under the naive policy follows the natural rate exactly. The difference between the interest rate paths indicates the substantial impact uncertainty has on optimal policy; the naive policy is between 50 and 150 basis points above the optimal policy for 2 years. This difference in policy has little impact on the output gap, but under optimal policy the inflation gap is closed much faster. The inflation gap is more negative under the naive policy because the interest rate is higher both initially and in the future since it does not take into account uncertainty about the ZLB. ${ }^{26}$ The Taylor rule prescribes rates above both the optimal and naive policies for most of the simulation period, and because agents are forward looking this feeds backward to cause much more negative gaps. ${ }^{27}$

Table 2 summarizes the distribution of outcomes under the three different policies based on simulating 50,000 paths drawn from the calibrated

25. In the online appendix we discuss the implications for our results of different values for the initial gaps, uncertainty, $\rho^{n}, \delta$, and $\xi$.

26. One might be surprised that inflation is far below target under the naive policy even though the output gap is near the target. This reflects the fact that we plotted the modal outcome, rather than the mean, and that the distributions of inflation and output gap outcomes are skewed to the left.

27. For some calibrations, the outcomes under the Taylor rule can be so poor that liftoff is delayed and rates are below the optimal policy throughout the simulation period. 
Figure 1. Liftoff in the Forward-Looking Model

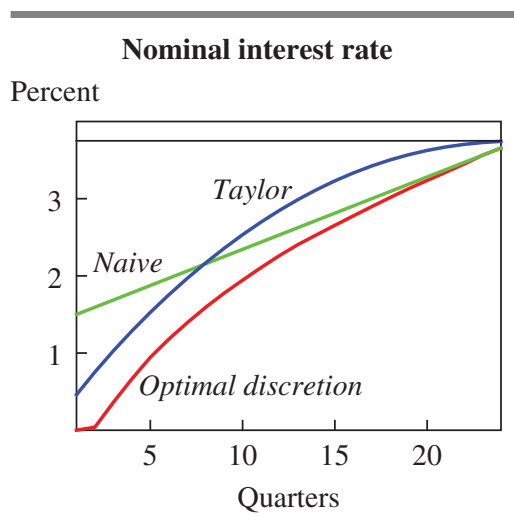

Inflation

Percent

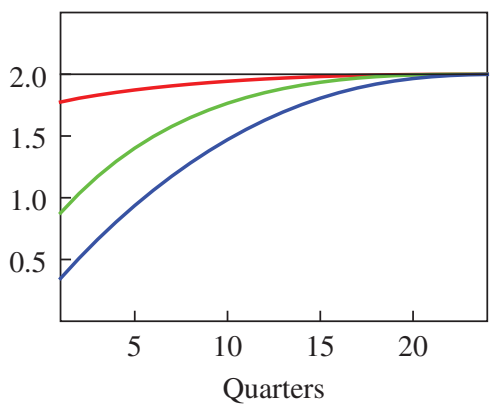

Output gap

Percent

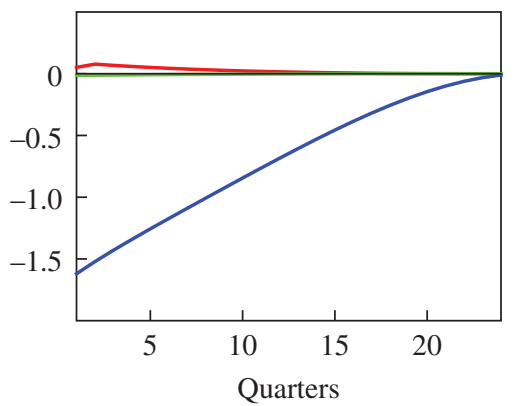

Source: Authors' calculations.

Table 2. Forward-Looking Simulation

\begin{tabular}{lccc}
\hline Statistic & Optimal discretion & Naive & Taylor rule \\
\hline Expected loss & 0.02 & 0.06 & 0.16 \\
Mean time at liftoff & 4.11 & 1.00 & 1.00 \\
Median time at liftoff & 3 & 1 & 1 \\
Median $\pi$ at liftoff & 1.81 & 0.88 & 0.35 \\
Median $x$ at liftoff & 0.08 & -1.44 & -1.62 \\
75th percentile maximum $(\pi)$ & 2.69 & 2.42 & 2.17 \\
25th percentile minimum $(x)$ & -0.72 & -1.44 & -2.63 \\
Median standard deviation $\Delta i$ & 1.87 & 1.88 & 0.97
\end{tabular}

Source: Authors' calculations. 
distributions of the shocks. Optimal discretion implies one-third the loss expected under the naive policy and one-eighth the loss expected under the Taylor rule. ${ }^{28}$ One way to interpret these losses is to calculate the per-period reduction in the output gaps and inflation gaps that would make the central banker indifferent between the outcomes under the optimal policy and those under the alternatives. Both gaps would have to be 43 percent and 65 percent smaller under the naive policy and the Taylor rule, respectively, to achieve this indifference. Under optimal discretion, the median liftoff (defined as the nominal interest rate exceeding 25 basis points) is delayed by 2 quarters compared to the other policies; the mean liftoff is delayed by more than 3 quarters, reflecting skewness in the outcomes. At the time of liftoff, inflation and output are much closer to the target under optimal discretion compared to the two alternative policies.

When comparing policies it is also important to assess how well each balances the risks of bad outcomes. We do this by comparing the 75th percentile across simulations of the maximum inflation gap and the 25th percentile of the lowest output gap over the first 6 years. Under optimal policy, the bad output outcomes are much lower than under either alternative policy. The bad inflation outcomes do not seem particularly high under any of the policies.

The statistic in the bottom row is the median standard deviation of changes in the nominal interest rate. By comparing interest rate volatility under the Taylor rule in our model with that implied by the same Taylor rule in the data, we can determine whether the uncertainty underlying our results is reasonable. If the volatility were much higher in our simulations we would conclude that it is unreasonably large. In fact, the 0.97 standard deviation in our Taylor rule simulations is only a little larger than the 0.88 standard deviation we find in our data. ${ }^{29}$ Interest rates are more volatile under both the optimal and naive policies because they respond to all fundamental shocks rather than to inflation and output alone. ${ }^{30}$

RESULTS FOR THE BACKWARD-LOOKING MODEL Figure 2 is the analog of figure 1 for the backward-looking model. The dynamics of return to target are quite different from those in the forward-looking model, but the key qualitative results are the same. As in the forward-looking model, optimal

28. The suboptimality of the Taylor rule does not hold by definition, because it provides commitment, which may lead to more favorable outcomes.

29. The online appendix describes how we calculate the interest rate implied by the Taylor rule with our data.

30. We thank Johannes Wieland for suggesting that we assess the volatility of the nominal interest rate. 
Figure 2. Liftoff in the Backward-Looking Model
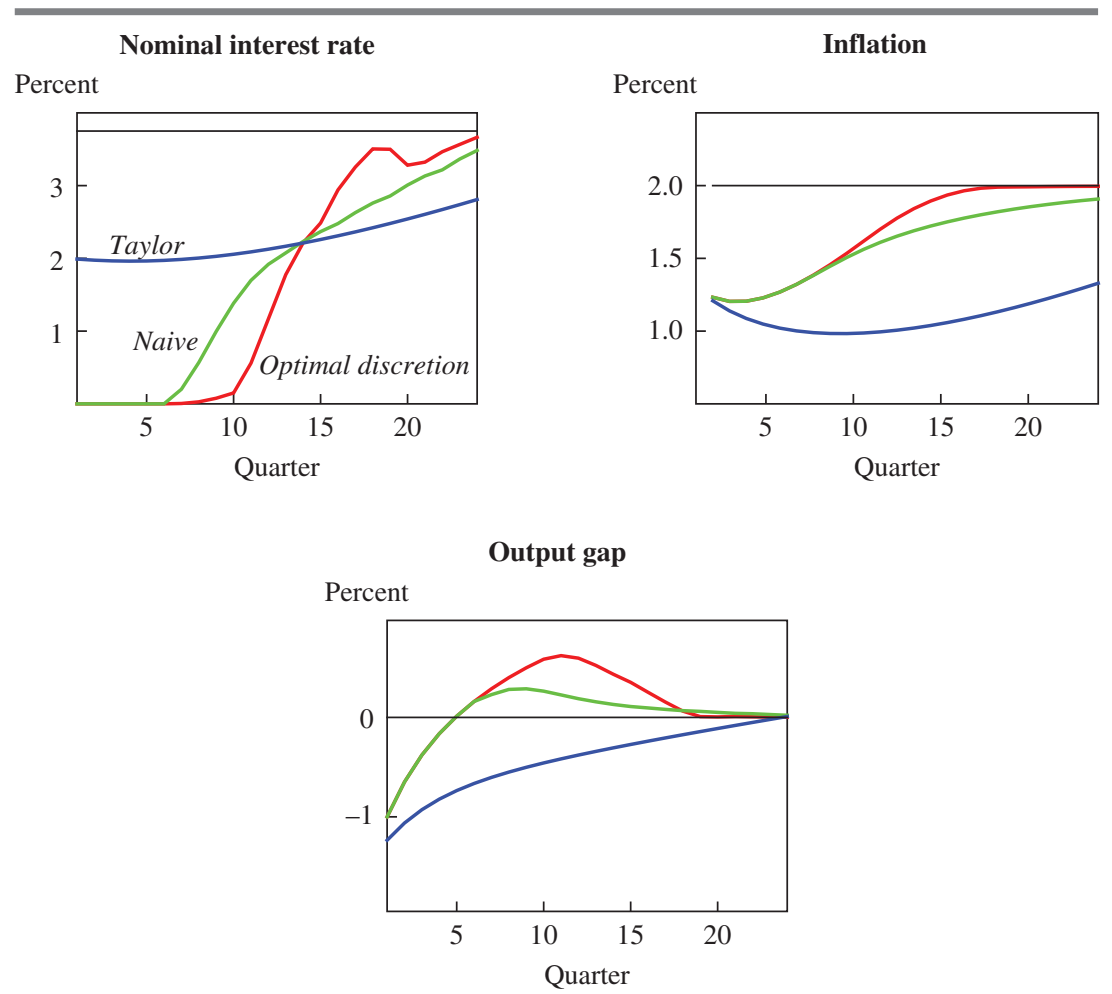

Source: Authors' calculations.

policy is substantially looser than both the naive policy and the Taylor rule. Here the optimal policy prescribes much more delay in lifting off from the ZLB. Delay now occurs under the naive policy because it is optimal to stimulate output strongly in order to return inflation to target, but this delay is shorter than under the optimal policy. The optimal policy also has a sharper liftoff than the naive policy. However, the increases under optimal policy are equivalent to just 25 basis points at each FOMC meeting, the same as the "measured pace" followed during the Fed tightening over 2004-06. Qualitatively, the differences in the output and inflation outcomes across the three policies are similar to those in the forwardlooking model as well. Taking into account uncertainty about the ZLB leads the optimal policy to return inflation to target faster than the naive policy, and it achieves this by allowing the output gap to overshoot more in order to build a buffer against the possibility of bad shocks in the future. 
Table 3. Backward-Looking Simulation

\begin{tabular}{lccc}
\hline Statistic & Optimal discretion & Naive & Taylor rule \\
\hline Expected loss & 0.27 & 0.28 & 0.60 \\
Mean time at liftoff & 12.5 & 10.3 & 1.00 \\
Median time at liftoff & 10 & 7 & 1 \\
Median $\pi$ at liftoff & 2.00 & 1.81 & 1.21 \\
Median $x$ at liftoff & 0.32 & 0.00 & -1.27 \\
75th percentile $\max (\pi)$ & 3.02 & 2.83 & 2.81 \\
25th percentile $\min (x)$ & -1.65 & -1.70 & -1.54 \\
Median standard deviation $\Delta i$ & 2.96 & 3.10 & 0.54 \\
\hline
\end{tabular}

Source: Authors' calculations.

Table 3 is constructed analogously to table 2. It shows that optimal policy provides only a marginal improvement over the naive policy in terms of expected losses, due to the offsetting effects of the inflation and output gaps. The median gaps are roughly closed at liftoff under both the optimal and naive policies, but they are quite large under the Taylor rule. The bad outcomes are similar across the three scenarios. Finally, note that the volatility of the interest rate under the Taylor rule is lower here compared to the data and the forward-looking model, so the underlying uncertainty is not excessive.

We conclude by illustrating one of the risks the optimal policy is able to address, namely the possibility that a shock will drive up inflation before the baseline liftoff. Figure 3 depicts a particular simulation where there is a large positive cost-push shock before the liftoff under the optimal policy shown in figure 2 . The shock triggers earlier liftoff under the optimal policy so that the inflation response is mild. The implication is that staying at zero longer under the optimal policy does not impair the ability of the central bank to respond to future contingencies. However, it does have to be prepared to raise rates promptly. We obtain similar results with the forwardlooking model.

\section{Historical Precedents for Risk Management}

The previous section demonstrates that the ZLB justifies a risk management approach to monetary policy. One may question whether following such an approach would be a departure from past FOMC behavior. Clearly, concerns about the ZLB are a relatively recent phenomenon. Nevertheless there are many reasons why a risk management approach can be justified when away from the ZLB, and we begin this section by reviewing them. We then demonstrate that the Federal Reserve has used risk management to justify its policy decisions over the period 1987-2008. 
Figure 3. Large Cost-Push Shock in the Backward-Looking Model

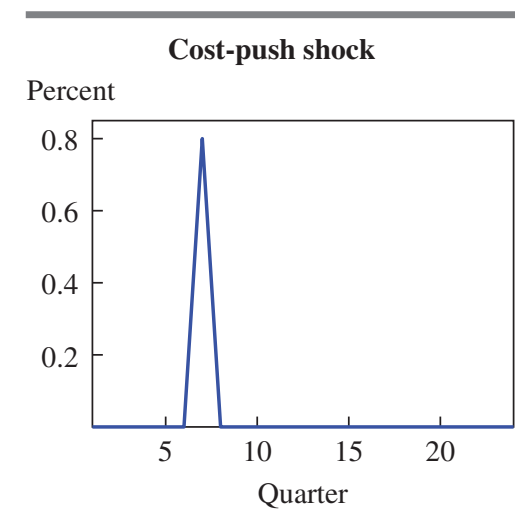

Output gap

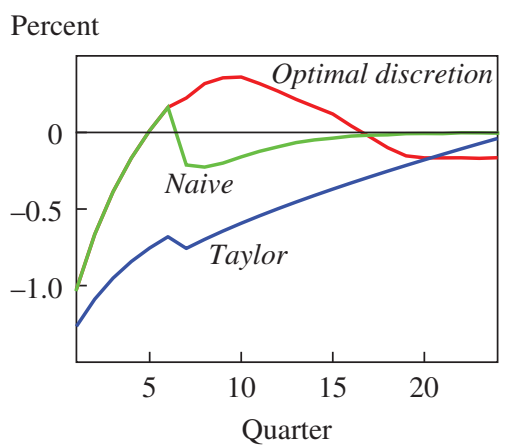

\section{Nominal interest rate}

Percent

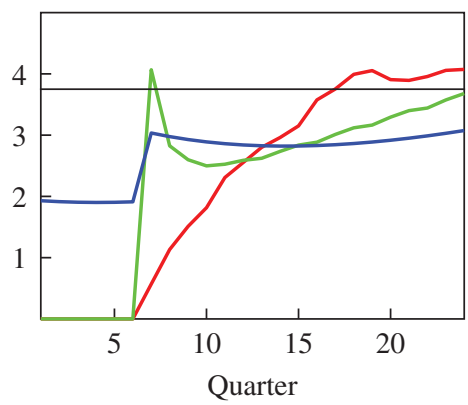

Inflation

Percent

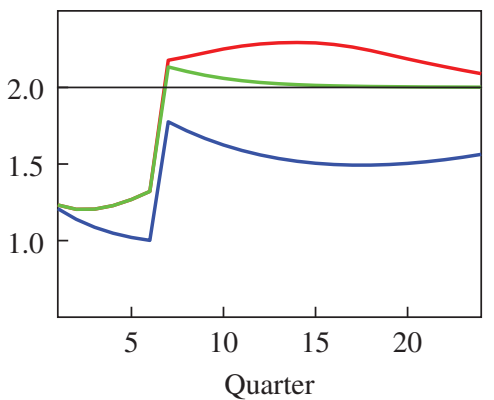

Source: Authors' calculations.

The FOMC minutes and other Federal Reserve communications reveal a number of episodes when uncertainty or insurance were used to justify the Fed's policy decisions. Sometimes the FOMC indicated that it had a wait-and-see approach to taking further actions or muted a funds rate move due to its uncertainty over the course of the economy or the extent to which early policy moves had yet shown through to economic activity and inflation. At other times the FOMC said its policy stance was taken in part as insurance against undesirable outcomes; during these times, the FOMC often noted that the potential costs of a policy overreaction likely were modest compared to the scenario it was insuring against.

Two episodes are particularly revealing. The first is the hesitancy of the FOMC to raise rates in 1997 and 1998 to counter inflationary threats 
because of uncertainty generated by the Asian financial crisis and the subsequent rate cuts following the Russian default. The second is the loosening of policy over 2000 and 2001, when uncertainty over the degree to which growth was slowing and the desire to insure against downside risks appeared to influence policy. Furthermore, in late 2001 the FOMC's aggressive actions also seemed to be influenced by attention to the risks associated with the ZLB on interest rates.

While the historical record is replete with references suggesting that the policy stance was influenced by uncertainty or insurance motives, this does not establish that risk management actually had a material impact on policy. Therefore, we conclude this section by quantifying these references into variables that we then use in section III to assess the importance of risk management for actual policy decisions.

\section{II.A. Rationales for Risk Management Away from the ZLB}

Policymakers have long emphasized the importance of uncertainty in their decision making. As Alan Greenspan (2004) put it: "The Federal Reserve's experiences over the past two decades make it clear that uncertainty is not just a pervasive feature of the monetary policy landscape; it is the defining characteristic of that landscape." ${ }^{\prime 1}$ This sentiment seems at odds with linear-quadratic models in which optimal policy involves adjusting the interest rate in response to only the mean of the distribution of shocks away from the ZLB. What kinds of factors cause departures from such conditions and justify the risk management approach?

Relaxing the assumption of a quadratic loss function is perhaps the simplest way to generate a rationale for risk management. The quadratic loss function is justified by Woodford (2003) as being a local approximation to consumer welfare. However, it might not be a good approximation when large shocks drive the economy far from the underlying trend; alternatively, it might simply be an inadequate approximation of FOMC behavior. Examples of models with asymmetric loss functions include those described by Paolo Surico (2007), Lutz Kilian and Simone Manganelli (2008), and Juan J. Dolado, P. Ramón María-Dolores, and Francisco Ruge-Murcia (2004). ${ }^{32}$ The model studied by the last authors implies that the optimal policy rule can involve nonlinear output gap and inflation terms if policymakers are

31. "Risk and Uncertainty in Monetary Policy," p. 36 (see note 2).

32. For an early contribution of the effects of asymmetric loss functions on stabilization policy see Friedman (1975). 
less averse to allowing output to run above potential than below it. The relevance of higher moments in the distribution of shocks for optimal policy is an obvious by-product of these nonlinearities.

Nonlinearities in economic dynamics are another natural motivation. For example, suppose recessions are episodes when self-reinforcing dynamics amplify the effects of downside shocks. This could be modeled as a dependence of current output on lagged output, as in our backwardlooking model, but with such dependence being concave rather than linear. Intuitively, negative shocks have a more dramatic effect on reducing future output than positive shocks have on increasing it, so greater uncertainty leads to looser optimal policy to guard against the more detrimental outcomes. Alternatively, suppose the Phillips curve is convex, perhaps owing to downward nominal wage rigidities that become more germane with low inflation. Here, a positive shock to the output gap leads to a significant increase of inflation above target while a negative shock leads to a much smaller decline in inflation. The larger the spread of these shocks, the greater the odds of experiencing a bad inflation outcome. Optimal policy guards against this, leading to a tightening bias. ${ }^{33}$ The risk management approach also appears in the large literature on how optimal monetary policy should adjust for uncertainty about the true model of the economy. Brainard (1967) derived the important result that uncertainty over the effects of policy should lead to caution and smaller policy responses to deviations from target. In contrast, the robust control analysis of Lars Hansen and Thomas Sargent (2008) has been interpreted to mean that uncertainty over model mis-specification should generate aggressive policy actions. As explained by Gadi Barlevy (2011), both the attenuation and aggressiveness results depend on the specifics of the underlying environment. Nonetheless, these analyses still often indicate that higher moments of the distribution of shocks can influence the setting of optimal policy.

\section{II.B. $1997-98$}

The year 1997 was a good one for the U.S. economy: real GDP increased $33 / 4$ percent (the March 1998 third estimate), the unemployment rate fell to 4.7 percent, and core CPI inflation was $2 \frac{1}{4} 4$ percent. With solid growth and

33. The fact that a convex Phillips curve can lead to a role for risk management has been discussed by Laxton, Rose, and Tambakis (1999) and Dolado, María-Dolores, and Naveira (2005). 
tight labor markets, the FOMC clearly was concerned about a buildup in inflationary pressures. As noted in the Federal Reserve's February 1998 Monetary Policy Report:

The circumstances that prevailed through most of 1997 required that the Federal Reserve remain especially attentive to the risk of a pickup in inflation. Labor markets were already tight when the year began, and nominal wages had started to rise faster than previously. Persistent strength in demand over the year led to economic growth in excess of the expansion of the economy's potential, intensifying the pressures on labor supplies. ${ }^{34}$

Indeed, over much of the period between early 1997 and mid-1998, the FOMC directive maintained a bias indicating that it was more likely to raise rates to battle inflationary pressures than it was to lower them. Nonetheless, the FOMC left the funds rate unchanged at 5.5 percent from March 1997 until September 1998. Why did it do so?

Certainly the inaction in large part reflected the forecast for growth to moderate to a more sustainable pace as well as the fact that actual inflation had remained contained despite tight labor market conditions. Based on the funds rate remaining at 5.5 percent, the Board of Governors' staff forecast in the August 1998 Greenbook projected GDP growth to slow from 2.9 percent in 1998 to 1.7 percent in 1999 . The unemployment rate was projected to rise to 5.1 percent by the end of 1999 and core CPI inflation was projected to edge down to 2.1 percent. Additionally, however, on several occasions heightened uncertainty over the outlook for growth and inflation apparently reinforced the decision to refrain from raising rates. The following quote from the July 1997 FOMC minutes is a revealing example:

While the members assessed risks surrounding such a forecast as decidedly tilted to the upside, the slowing of the expansion should keep resource utilization from rising substantially further, and this outlook together with the absence of significant early signs of rising inflationary pressures suggested the desirability of a cautious "wait and see" policy stance at this point. In the current uncertain environment, this would afford the FOMC an opportunity to gauge the momentum of the expansion and the related degree of pressure on resources and prices. ${ }^{35}$

Furthermore, the FOMC did not regard "waiting and seeing" as having a high cost. They thought any increase in inflation would be slow and that,

34. Available at http://www.federalreserve.gov/boarddocs/hh/1998/february/Report Section1.htm

35. Available at http://www.federalreserve.gov/fomc/minutes/19970701.htm 
if needed, a limited tightening would be sufficient to rein in any emerging price pressures. This is seen in the following quote from the same meeting:

The risks of waiting appeared to be limited, given that the evidence at hand did not point to a step-up in inflation despite low unemployment and that the current stance of monetary policy did not seem to be overly accommodative.

... In these circumstances, any tendency for price pressures to mount was likely to emerge only gradually and to be reversible through a relatively limited policy adjustment.

Thus, it appears that uncertainty and associated risk management considerations supported the FOMC's decision to leave policy on hold.

Of course, the potential fallout for the U.S. economy of the Asian financial crisis was a major factor underlying the uncertainty about the outlook. The baseline scenario was that the associated weakening in demand from abroad and a stronger dollar would be enough to keep inflationary pressures in check but would not be strong enough to cause inflation or employment to fall too low. As Chairman Greenspan noted in his February 1998 Humphrey-Hawkins testimony to Congress, there were substantial risks to this outlook, with the delicate balance dictating unchanged policy:

However, we cannot rule out two other, more worrisome possibilities. On the one hand, should the momentum to domestic spending not be offset significantly by Asian or other developments, the U.S. economy would be on a track along which spending could press too strongly against available resources to be consistent with contained inflation. On the other, we also need to be alert to the possibility that the forces from Asia might damp activity and prices by more than is desirable by exerting a particularly forceful drag on the volume of net exports and the prices of imports. When confronted at the beginning of this month with these, for the moment, finely balanced, though powerful forces, the members of the Federal Open Market Committee decided that monetary policy should most appropriately be kept on hold. ${ }^{36}$

By late in the summer of 1998, this balance had changed, as the strains following the Russian default weakened the outlook for foreign growth and tightened financial conditions in the United States. The FOMC was concerned about the direct implications of these developments for U.S. financial markets, already evident in the data, as well as their implications for the real economy, which were still just a prediction. The staff forecast

36. "Coming Budgetary Challenges," Testimony of Chairman Alan Greenspan before the Committee on the Budget, U.S. House of Representatives, March 4, 1998. Available at http://www.federalreserve.gov/boarddocs/testimony/1998/19980304.htm 
prepared for the September FOMC meeting reduced the projection for growth in 1999 by about $1 / 2$ percentage point to $1 \frac{1 / 4}{4}$ percent, predicated on a 75 basis-point reduction in the funds rate spread out over three quarters. Such a forecast was not a disaster-indeed, at 5.2 percent the unemployment rate projected for the end of 1999 was still below the staff's estimate of its natural rate. Nonetheless, the FOMC moved much faster than the staff assumed it would, lowering rates 25 basis points at its September and November meetings as well as making an inter-meeting rate cut in October. According to the FOMC minutes, the rate cuts were made in part as insurance against a worsening of financial conditions and weakening activity. As they noted in September of that year:

Such an action was desirable to cushion the likely adverse consequences on future domestic economic activity of the global financial turmoil that had weakened foreign economies and of the tighter conditions in financial markets in the United States that had resulted in part from that turmoil. At a time of abnormally high volatility and very substantial uncertainty, it was impossible to predict how financial conditions in the United States would evolve ... In any event, an easing policy action at this point could provide added insurance against the risk of a further worsening in financial conditions and a related curtailment in the availability of credit to many borrowers. ${ }^{37}$

While the references to insurance are clear, a case also can be made that these policy moves were undertaken largely to realign the misses in the expected paths for growth and inflation from the FOMC's policy goals. At that time, the prescriptions to address the risks to their policy goals were in conflict: risks to achieving the inflation mandate called for higher interest rates while risks to achieving the maximum employment mandate called for lower rates. As the above quote from Chairman Greenspan's February 1998 testimony indicated, in early 1998 the FOMC thought that a $5 \frac{1}{2}$ percent funds rate kept these risks in balance. Subsequently, as the odds of economic weakness increased, the FOMC cut rates to bring the risks to the two goals back into balance. As Chairman Greenspan said in his February 1999 Humphrey-Hawkins testimony:

To cushion the domestic economy from the impact of the increasing weakness in foreign economies and the less accommodative conditions in U.S. financial markets, the FOMC, beginning in late September, undertook three policy easings. . . .

37. Minutes of the Federal Open Market Committee, September 29, 1998. Available at http://www.federalreserve.gov/fomc/minutes/19980929.htm 
These actions were taken to rebalance the risks to the outlook, and, in the event, the markets have recovered appreciably. ${ }^{38}$

Were the late 1998 rate moves a balancing of forecast probabilities, insurance against a downside skew in possible outcomes, or some combination of both? There is no easy answer. This motivates our econometric work in section III, which seeks to disentangle the normal response of policy to expected outcomes from uncertainty and other related factors that may have influenced the policy decision.

\section{II.C. $2000-01$}

In the end, the economy weathered the fallout from the Russian default well. The strength of the U.S. economy and underlying inflationary pressures led the FOMC to execute a series of rate hikes that brought the funds rate up to 6.5 percent by May of 2000. At the time of the June 2000 FOMC meeting, the unemployment rate stood at 4.1 percent and core PCE inflation, which the FOMC was now using as its main measure of consumer price inflation, was running at about $13 / 4$ percent, up from $1 \frac{1}{2}$ percent in 1999 . The staff forecast that growth would moderate to a rate near or a little below potential, the unemployment would remain near its current level, and inflation would rise to 2.3 percent in 2001and this forecast was predicated on another 75 basis points tightening. Despite this outlook, the FOMC decided to leave rates unchanged. What drove this pause? It seems likely to us that risk management was an important consideration.

In particular, the FOMC appeared to want to see how uncertainty over the outlook would play out. First, the incoming data and anecdotal reports from committee members' business contacts pointed to a slowdown in growth, although how much it was slowing was unclear. Second, with rates having risen substantially over the previous year, and given the lags from policy changes to economic activity, it was unlikely that the full effects of the hikes had yet been felt. Given the relatively high level of the funds rate and the slowdown in growth that appeared in train, the FOMC seemed wary of over-tightening. Third, despite the staff forecast, the FOMC apparently considered the costs of waiting, in terms of inflation risks, to be small.

38. "The Federal Reserve's Semiannual Report on Monetary Policy," Testimony of Chairman Alan Greenspan before the Committee on Banking, Housing, and Urban Affairs, U.S. Senate, February 23, 1999. Available at http://www.federalreserve.gov/boarddocs/ hh/1999/february/testimony.htm 
Accordingly, the FOMC thought it better to put a rate increase on hold and see how the economy evolved. The June 2000 FOMC minutes contain a good deal of commentary supporting this interpretation: ${ }^{39}$

The increasing though still tentative indications of some slowing in aggregate demand, together with the likelihood that the earlier policy tightening actions had not yet exerted their full retarding effects on spending, were key factors in this decision. The uncertainties surrounding the outlook for the economy, notably the extent and duration of the recent moderation in spending and the effects of the appreciable tightening over the past year ... reinforced the argument for leaving the stance of policy unchanged at this meeting and weighting incoming data carefully. ... Members generally saw little risk in deferring any further policy tightening move, particularly since the possibility that underlying inflation would worsen appreciably seemed remote under prevailing circumstances. ${ }^{40}$

In the second half of 2000 it became increasingly evident that growth had slowed to a pace somewhat below trend and inflation was moving up at a slower pace than the staff had projected in June. The FOMC's response was to hold the funds rate at 6.5 percent through the end of 2000. But the data around the turn of the year proved to be weaker than anticipated. In a conference call on January 3, 2001, the FOMC cut the funds rate to 6 percent, and then at its end-of-month meeting it lowered the rate again, to $5 \frac{1}{2}$ percent. $^{41}$

In justifying the aggressive ease, the minutes stated:

Such a policy move in conjunction with the 50 basis point reduction in early January would represent a relatively aggressive policy adjustment in a short period of time, but the members agreed on its desirability in light of the rapid weakening in the economic expansion in recent months and associated deterioration in business and consumer confidence. The extent and duration of the current economic correction remained uncertain, but the stimulus . . would help guard against cumulative weakness in economic activity and would support the positive

39. The FOMC had already invoked such arguments earlier in this cycle. As noted in the July 2000 Monetary Policy Report: "The FOMC considered larger policy moves at its first two meetings of 2000 but concluded that significant uncertainty about the outlook for the expansion of aggregate demand in relation to that of aggregate supply, including the timing and strength of the economy's response to earlier monetary policy tightenings, warranted a more limited policy action." (Monetary Policy Report forwarded to Congress on July 20, 2000, available at http://www.federalreserve.gov/boarddocs/hh/2000/July/Report Section1.htm)

40. Minutes of the Federal Open Market Committee, June 27-28, 2000. http://www. federalreserve.gov/fomc/minutes/20010131.htm

41. At that meeting the Federal Reserve Board staff was forecasting that growth would stagnate in the first half of the year but that the economy would avoid an outright recession even with the funds rate at 5.75 percent. Core PCE inflation was projected to rise modestly to a little under 2.0 percent. 
factors that seemed likely to promote recovery later in the year ... In current circumstances, members saw little inflation risk in such a "front-loaded" easing policy, given the reduced pressures on resources stemming from the sluggish performance of the economy and relatively subdued expectations of inflation. ${ }^{42}$

According to this quote, not only was the actual weakening in activity an important consideration in the policy decision, but uncertainty over the extent of the downturn and the possibility that it might turn into an outright recession seemed to spur the FOMC to make a large move. The "help guard against cumulative weakness" and "front-loaded" language could be read as the FOMC taking out some additional insurance against the possibility that the weakening activity would snowball into a recession. This could have reflected a concern about the kinds of nonlinear output dynamics or perhaps non-quadratic losses associated with a large recession that we discussed in section II.A.

The FOMC steadily brought the funds rate down further over the course of 2001, against a backdrop of weakening activity, and the economy seemed to be skirting a recession. Then the tragic events of September 11 occurred. There was, of course, huge uncertainty over how international developments, logistics disruptions, and the sentiment of households, businesses, and financial markets would affect spending and production. By November the board staff was forecasting a modest recession: growth in the second half of 2001 was projected to decline $1 \frac{1}{2}$ percent at an annual rate and rise at just a $1 \frac{1}{4}$ percent rate in the first half of 2002. By the end of 2002 the unemployment rate was projected to rise to 6.1 percent and core PCE inflation was projected to be $1 \frac{1}{2}$ percent. These forecasts were predicated on the funds rate remaining flat at $2 \frac{1}{4}$ percent.

However, in the aftermath of the terrorist attacks the FOMC was worried about something more serious than the shallow recession forecast by the staff. Furthermore, a new risk came to light, namely the chance that disinflationary pressures might emerge that, once established, would be more difficult to fight with the funds rate already low. In response, the FOMC again acted aggressively, cutting the funds rate 50 basis points in a conference call on September 17 and again at their regular meetings in October and November. The November 2001 FOMC meeting minutes note:

... members stressed the absence of evidence that the economy was beginning to stabilize and some commented that indications of economic weakness had in fact intensified. Moreover, it was likely in the view of these members that

42. Minutes of the Federal Open Market Committee, January 30-31, 2001. Available at http://www.federalreserve.gov/fomc/minutes/20010131.htm 
core inflation, which was already modest, would decelerate further. In these circumstances insufficient monetary policy stimulus would risk a more extended contraction of the economy and possibly even downward pressures on prices that could be difficult to counter with the current federal funds rate already quite low. Should the economy display unanticipated strength in the near term, the emerging need for a tightening action would be a highly welcome development that could be readily accommodated in a timely manner to forestall any potential pickup in inflation. ${ }^{43}$

This passage suggests that the large rate cuts were not only aimed at preventing the economy from falling into a serious recession with deflationary consequences, but that the FOMC was also concerned that such an outcome "could be difficult to counter with the current funds rate already quite low." Accordingly, the aggressive policy moves could in part also have reflected insurance against the future possibility of being constrained by the ZLB, precisely the policy scenario and optimal policy prescription described in section I.

\section{II.D. Quantifying References to Uncertainty and Insurance in FOMC Minutes}

We have shown that Federal Reserve communications contain many references suggesting that uncertainty or insurance motives influenced the stance of policy. But the question remains: Has risk management had a material impact on policy? We now show how we quantified these references into variables that can be used to assess the importance of risk management for actual policy decisions.

In the spirit of the narrative approach pioneered by Christina Romer and David Romer (1989), we built judgmental indicators based on our reading of the FOMC minutes covering the period from the beginning of Greenspan's chairmanship in 1987 to 2008 . We concentrated on the paragraphs that describe the FOMC's rationale for its policy decision, reading these passages for references to when uncertainty or insurance considerations appeared closely linked to the FOMC's decision. Other portions of the minutes were excluded from our analysis in order to better isolate arguments that directly influenced the policy decision from more general discussions of unusual data or forecast uncertainty.

43. Minutes of the Federal Open Market Committee, November 6, 2001. A transcript is available at https://www.andrew.cmu.edu/course/88-301/monetarism/minutes-0111.pdf 
We constructed two separate judgmental variables, one for uncertainty ( $h U n c$ ) and one for insurance (hIns), where "h" stands for "human-coded." The uncertainty variable was coded to plus (minus) one if we judged that the FOMC appealed to uncertainty to position the funds rate higher (lower) than it otherwise would be based on the staff forecast alone. If uncertainty did not appear to be an important factor influencing the policy decision, we coded the indicator as zero. We coded the insurance variable similarly by identifying when the minutes cited insurance against some adverse outcome as an important consideration in the stance of policy. ${ }^{44}$

As an example of our coding, consider the June 2000 meeting discussed above when the FOMC decided to wait to assess future developments before taking further policy action. The commentary below highlights the role of uncertainty in this decision (our italics):

The increasing though still tentative indications of some slowing in aggregate demand, together with the likelihood that the earlier policy tightening actions had not yet exerted their full retarding effects on spending, were key factors in this decision. The uncertainties surrounding the outlook for the economy, notably the extent and duration of the recent moderation in spending and the effects of the appreciable tightening over the past year, including the $1 / 2$ percentage point increase in the intended federal funds rate at the May meeting, reinforced the argument for leaving the stance of policy unchanged at this meeting and weighting incoming data carefully. ${ }^{45}$

We coded this meeting as a minus one for $h U n c$-rates were lower because uncertainty over the economic outlook and the effects of past policy moves appear to have been important factors in the FOMC's decision not to raise rates. Similarly, the January and November 2001 quotes cited above led us to code hIns as a minus one for those meetings, since, as we noted in the narrative, the FOMC appeared to be making aggressive rate moves in part to insure against downside risks to the baseline scenario.

We did not code all mentions of uncertainty or insurance as a plus or minus one. For example, the March 1998 minutes referred to uncertainties over the economic outlook and said that the FOMC could wait for further developments before tightening to counter potential inflation developments.

44. A value of plus (minus) one for either variable could reflect the FOMC raising (lowering) rates by more (less) than they would have if they ignored uncertainty or insurance or a decision to keep the funds rate at its current level when a forecast-only call would have been to lower (raise) rates.

45. See note 40. 
However, at that time the FOMC was not obviously in the midst of a tightening cycle; the baseline forecast seemed consistent with the funds rate setting at the time; and the commentary over the need to tighten was in reference to an indefinite point in the future. So, in our judgment, uncertainty did not appear to be a very important factor holding back a rate increase at that meeting, and we coded it as a zero. ${ }^{46}$

Of course, this coding of the minutes is inherently subjective, and there is no definitive way to judge the accuracy of the decisions we made. Consequently we also constructed objective measures of how often references to uncertainty or insurance appeared in the policy paragraphs of the minutes. In particular, we constructed variables which measure the percentage of sentences containing words related to uncertainty or insurance in conjunction with references to economic activity, inflation, or both. ${ }^{47}$ The measures for uncertainty and insurance are denoted $m U n c$ and $m I n s$, where " $m$ " indicates these variables are "machine-coded." Figures 4 and 5 show plots of our minutes-based uncertainty and insurance variables.

Non-zero values of the human-coded variables are indicated by dots and the bars indicate the machine-coded sentence counts. The uncertainty indicator $h U n c$ "turns on" in 31 out of the 128 meetings between 1993 and 2008. Indications that insurance was an actor in shading policy are not as common, but still show up 14 times in hIns. Most of the time-24 for uncertainty and 11 for insurance-we judged that rates were set lower than they otherwise would have been to account for these factors.

The $h U n c$ and hIns codings are not always reflected in the sentence counts. There are also meetings where the sentence counts are positive but we did not judge them to indicate that rates were set differently than they normally would have been. For example, in March 2007 hUnc is coded zero for uncertainty whereas $m U n c$ finds uncertainty referenced in nearly one-third of the sentences in the policy section of the minutes. Inspection of the minutes indicates that the FOMC was uncertain over both the degree to which the economy was weakening and whether their expectation of a decline in inflation, which was running uncomfortably high at the time,

46. From the minutes: "Should the strength of the economic expansion and the firming of labor markets persist, policy tightening likely would be needed at some point to head off imbalances that over time would undermine the expansion in economic activity. Most saw little urgency to tighten policy at this meeting, however... (o)n balance, in light of the uncertainties in the outlook and given that a variety of special factors would continue to contain inflation for a time, the Committee could await further developments bearing on the strength of inflationary pressures without incurring a significant risk."

47. The appendix describes our coding algorithm in more detail. 
Figure 4. Minutes-Based Uncertainty Variables

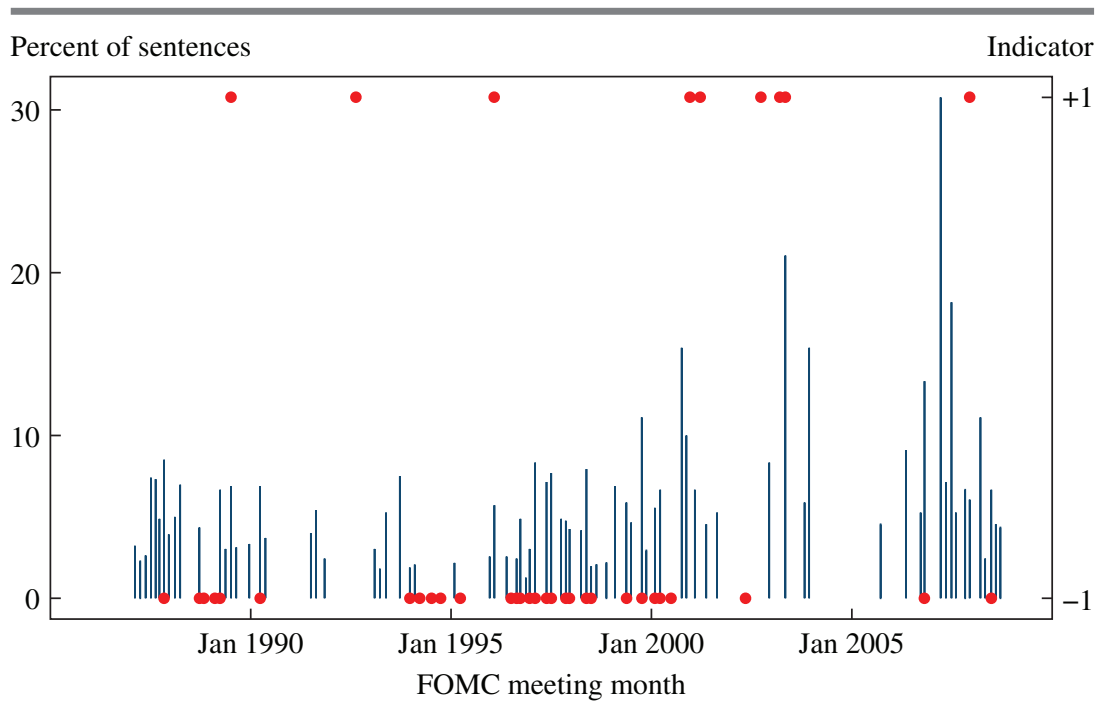

Source: Authors' calculations based on FOMC minutes; see text.

Figure 5. Minutes-Based Insurance Variables

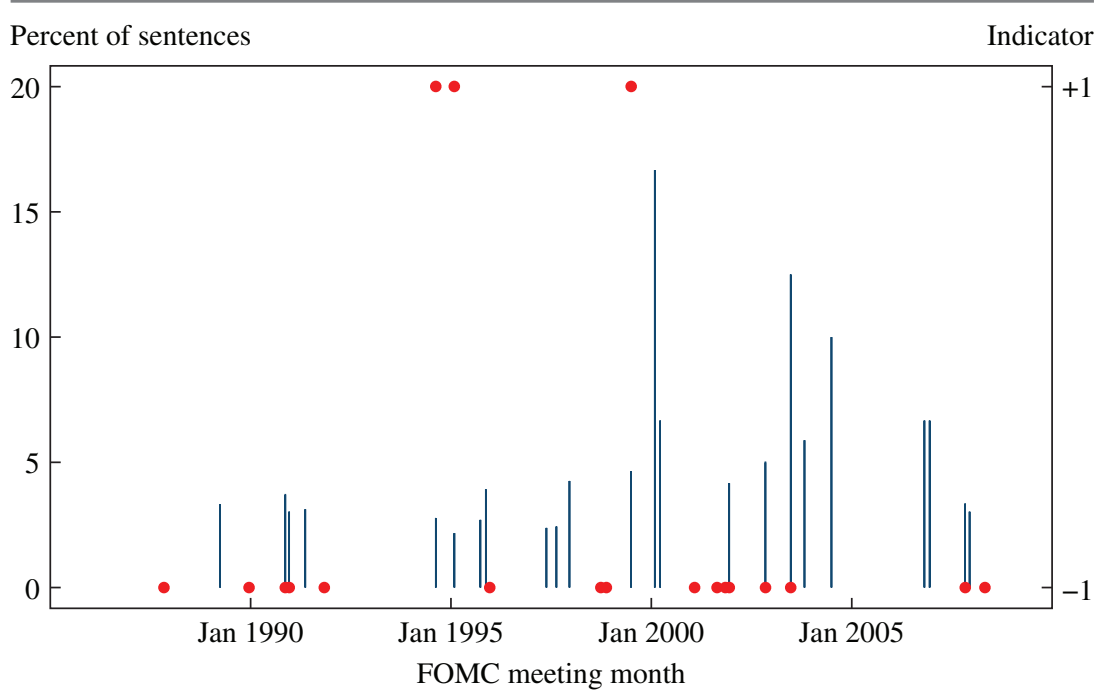

Source: Authors' calculations based on FOMC minutes; see text. 
actually would materialize. In the end, they did not adjust current policy in response to these conflicting uncertainties. Hence we coded $h U n c$ to zero in this case.

Note that we did not attempt to measure a variable for risk management per se. The minutes often contain discussions of policies aimed at addressing risks to attaining the FOMC's goals. However, many times this commentary appears to surround policy adjustments aimed instead at balancing (possibly conflicting) risks to the outlook for output and inflation, not unlike the response to changes in economic conditions prescribed by the canonical framework for studying optimal policy under discretion. Such risk balancing was discussed in our narrative of the 1997-98 period..$^{48}$

\section{Econometric Evidence of Risk Management}

So far we have uncovered clear evidence that risk management considerations have been a pervasive feature of Federal Reserve communications. But it is not clear at this stage whether risk management has had a material impact on the FOMC's policy decisions. If it has, then calling for a risk management approach in the current policy environment would be consistent with a well established approach to monetary policy. In this section we describe econometric evidence suggesting that risk management has had a material impact on the FOMC's funds rate choices in the pre-ZLB era.

We estimate monetary policy reaction functions of the kind studied by Clarida, Galí, and Gertler (2000) and many others. These have the funds rate set as a linear function of output gap and inflation forecasts; there is no role for risk management unless risk feeds directly into the point forecasts. To quantify the role of risk beyond such a direct influence we add variables that proxy for risk to the reaction function. ${ }^{49}$

48. Indeed, for much of our sample period, the FOMC discussed risks about the future evolution of output or inflation in order to signal a possible bias in the direction of upcoming rate actions. For example, in the July 1997 meeting described earlier, the minutes indicate: "An asymmetric directive was consistent with their view that the risks clearly were in the direction of excessive demand pressures." Since the FOMC delayed tightening at this meeting, this "risk" reference communicated that the risks to price stability presented by the baseline outlook would likely eventually call for rate increases. But it does not appear to be a reference that variance or skewness in the distribution of possible inflation outcomes should dictate some non-standard policy response.

49. There is a large literature that examines nonlinearities in policy reaction functions (see Gnabo and Moccero [2015], Mumtaz and Surico [2015], and Tenreyro and Thwaites [2015] for reviews of this literature and recent estimates), but surprisingly little work that speaks directly to risk management. We discuss the related literature below. 


\section{III.A. Empirical Strategy}

Let $R_{t}^{*}$ denote the notional target for the funds rate in period $t$. We assume the FOMC sets this target according to

$$
R_{t}^{*}=R^{*}+\beta\left(E_{t}\left[\pi_{t, k}\right]-\pi^{*}\right)+\gamma E_{t}\left[x_{t, q}\right]+\mu s_{t},
$$

where $\pi_{t, k}$ denotes the average annualized inflation rate from $t$ to $t+k$, $\pi^{*}$ is the FOMC's target for inflation, $x_{t, q}$ is the average output gap from $t$ to $t+q, s_{t}$ is a risk management proxy, and $E_{t}$ denotes expectations conditional on information available to the FOMC at date $t$. The coefficients $\beta, \gamma$, and $\mu$ are fixed over time. $R^{*}$ is the desired nominal rate when inflation is at target, the output gap is closed, and risk does not influence policy other than through the forecast, $\mu=0$. If the average output and inflation gaps are both zero and the FOMC acts as if the natural rate is constant and out of its control, then $R^{*}=r^{*}+\pi^{*}$, where $r^{*}$ is the real natural rate of interest. ${ }^{50}$

We make two more assumptions to arrive at our estimation equation. First, the FOMC has a preference for interest rate smoothing and so does not choose to hit its notional target instantaneously, and as a practical matter it is necessary to include lags of the funds rate to fit the data. Second, the FOMC does not have perfect control over interest rates, which gives rise to an error term, $v_{t}$. These assumptions lead to the following specification for the actual funds rate, $R_{t}$ :

$$
R_{t}=(1-A(1)) R_{t}^{*}+A(L) R_{t-1}+v_{t},
$$

where $A(L)=\sum_{j=0}^{N-1} a_{j+1} L^{j}$ is a polynomial in the lag operator $L$ with $N$ denoting the number of funds rate lags. The error term $v_{t}$ is assumed to be mean zero and serially independent. Combining equations 13 and 14 yields our estimation equation:

$$
R_{t}=b_{0}+b_{1} E_{t}\left[\pi_{t, k}\right]+b_{2} E_{t}\left[x_{t, q}\right]+A(L) R_{t-1}+b_{3} s_{t}+v_{t},
$$

where $b_{i}, i=0,1,2,3$ are simple functions of $A(1), \beta, \gamma, \mu, r^{*}$ and $\pi^{*} .^{51}$

50. There is no presumption that (equation 13) reflects optimal policy and so assuming a constant natural rate is not inconsistent with our theoretical analysis. We explored using forecasted growth in potential output derived from board staff forecasts to proxy for the natural rate and found this did not affect our results.

51. We make no attempt to address the possibility of hitting the ZLB in our estimation. See Chevapatrakul, Kim, and Mizen (2009) and Kiesel and Wolters (2014) for papers that do this. 
We use the publicly available Federal Reserve Board staff forecasts of core CPI inflation (in percentage points) and the output gap (percentage point deviations of real GDP from its potential) to measure $E_{t}\left[\pi_{t, k}\right]$ and $E_{t}\left[x_{t, q}\right]$ with $k=q=3 .^{52}$ These forecasts are available for every FOMC meeting. We estimate equation 15 both meeting-by-meeting and quarterby-quarter. ${ }^{53}$ When we estimate it at the quarterly frequency we use staff forecasts corresponding to FOMC meetings closest to the middle of each quarter. ${ }^{54}$ We measure $R_{t}$ at the meeting frequency using the funds rate target announced (or estimated) at the end of the day of a meeting, and we measure it at the quarterly frequency using the average effective funds rate over the 30 trading days following the meeting closest to the middle of the quarter. Provided the error term $v_{t}$ is serially uncorrelated and is orthogonal to the forecasts and the risk proxies, we can obtain consistent estimates of $\beta, \gamma$, and $\mu$ by estimating equation 15 by ordinary least squares. We keep $N$ sufficiently large to ensure that $v_{t}$ is serially uncorrelated.

To quantify the role of risk we study the magnitude and statistical significance of estimates of $\mu$ in equation 13. An insignificant estimate of $\mu$ cannot be interpreted as evidence against a role for risk management, because risk might operate by influencing point forecasts as in our forward-looking model. We also could find no effect because risk might tilt policy in opposite directions depending on the circumstances. With the exception of our human-coded FOMC-based variables, none of our risk proxies accounts for the fact that perceived risks to the forecast might have different effects on policy depending on the nature of the risk and the state of the economy. For example, an increase in uncertainty about the inflation outlook should lead to tight policy if this increase occurs during a period of heightened concerns about rising inflation, but to looser policy if concerns are over unwanted disinflation. As such, estimates of the effect of any given proxy will at best reflect the nature of the risk and the circumstances in which it has arisen that have predominated over the sample period.

Finally, we do not allow for the coefficients on the forecasts to depend on our risk proxies as is suggested by the work of Brainard (1967) and others. However, we show in the online appendix that if these forecast coefficients are linear functions of risk, then the null hypothesis that a given

52. The online appendix describes our data in more detail.

53. We assume meetings are equally spaced even though this is not true in practice. We account for this discrepancy when we calculate standard errors by allowing for heteroskedasticity.

54. Gnabo and Moccero (2015) also estimate quarterly reaction functions using board staff forecasts. 
proxy's coefficient is zero in our now mis-specified model encompasses the null that the forecast coefficients are invariant to risk as measured by that proxy.

\section{III.B. Proxies for Risk Management}

In addition to our human- and machine-coded FOMC-based variables we consider several proxies for risk management that do not rely on interpreting the FOMC minutes. Two of these variables are constructed using the Federal Reserve Board staff's forecast, which is seen by the FOMC at its regular meetings, and we study them using our meeting frequency reaction functions. The remaining variables are measured at the quarterly frequency and can be divided into two groups based on whether they primarily reflect variance or skewness in the forecast.

The two additional FOMC-based proxies involve revisions to the Federal Reserve Board staff's forecasts for the output gap (frGap) and core CPI inflation (frInf). The revisions correspond to changes between meeting $m$ and $m-1$ in the forecasts over the same one-year period that starts in the quarter of meeting $m-1$. A big change in the forecast is usually triggered by unusual events that may be difficult to interpret and hence generate uncertainty about the forecast. If the FOMC were only worried about these events in making its point forecast, then the post-shock forecasts of the output gap or inflation would be sufficient to describe the policy setting. However, if uncertainty has a separate effect on policy the forecast revisions might enter significantly.

Three of the quarterly proxies exploit financial market data: VXO, SPD, and JLN. VXO is the Chicago Board Options Exchange's measure of market participants' expectations of volatility in the S\&P 500 stock index over the next 30 days. Since the S\&P 500 reflects earnings expectations, VXO should, at least in part, measure market participants' uncertainty about the economic outlook.$^{55}$ SPD is the difference between the quarterly average of daily yields on BAA corporate bonds and 10-year Treasury bonds. Gilchrist and Zakrajšek (2012) demonstrate that this variable measures private-sector default risk plus other factors that may indicate downside risks to economic growth. ${ }^{56} \mathrm{JLN}$ is Kyle Jurado, Sydney Ludvigson, and

55. Using a VAR framework Bekaert, Hoerova, and Lo Duca (2013) find weak evidence that positive innovations to VXO lead to looser policy. Gnabo and Moccero (2015) find that policy responds more aggressively to economic conditions and is less inertial in periods of high uncertainty as measured by VXO.

56. Alcidi, Flamini, and Fracasso (2011), Castelnuovo (2003), and Gerlach-Kristen (2004) consider reaction functions including SPD. 
Serena Ng's (2015) measure of the common variation in the one-year-ahead unforecastable components of a large number of activity, inflation, and financial indicators. Given its basis in measuring uncertainty about macroeconomic forecasts, JLN is a natural risk proxy to consider. But, unlike VXO and SPD, it does not measure real-time uncertainty, and similar to these two measures it confounds macroeconomic and financial uncertainty.

The remaining proxies are based on the Survey of Professional Forecasters (SPF) which surveys forecasters about their point forecasts of GDP growth and GDP deflator inflation and their probability distributions for these forecasts. We use both kinds of information to construct measures of variance and skewness in the economic outlook one year ahead. ${ }^{57}$ Variance is measured using the median among forecasters of the standard deviations calculated from each individual's probability distribution (vGDP and vInf) and the interquartile range of point forecasts across individuals (DvGDP and DvInf. $)^{58}$ Skewness is measured using the median of the individual forecasters' mean minus mode (sGDP and sInf) and the difference between the mean and the mode of the cross-forecaster distribution of point forecasts (DsGDP and DsInf). Consequently, a positive (negative) value for one of these proxies represents upside (downside) risk to the modal forecast.

The principal advantage of these proxies is that they are real-time measures of perceived risks in the forecast. The main drawback of the measures based on survey respondents' forecast distributions is that the bins they are asked to put probability mass on are relatively wide, so statistics based on them may contain substantial measurement error. The proxies based on the cross-section of forecasts are properly thought of as measuring forecaster disagreement rather than variance or skewness in the outlook per se. However, there is a large literature that uses forecaster disagreement as a proxy for perceived risk. ${ }^{59}$

All estimates are based on samples that end in 2008 to avoid the ZLB period but begin at different dates to address idiosyncratic features of the data. The benchmark start date is determined by the onset of Alan Greenspan's tenure as chairman of the FOMC in 1987, but later dates are used in several cases. The sample for the FOMC-based indicators starts in 1993

57. The forecast distributions are for growth and inflation in the current and following year. We use D'Amico and Orphanides' (2014) procedure to translate these into distributions of four-quarter-ahead forecasts.

58. Gnabo and Moccero (2014) find statistically insignificant effects of DvInf on monetary policy.

59. As discussed by Baker, Bloom, and Davis (2015) there is no consensus on how good a proxy it is. Note that we do not study Baker, Bloom, and Davis's (2015) measure of uncertainty since it confounds uncertainty about monetary policy and the economic outlook. 
because inter-meeting changes in the target funds rate were much more common prior to that year than afterwards; the FOMC often voted on a bias to future policy moves and the chairman subsequently acted at his discretion. We cannot use inter-meeting moves because we lack contemporaneous staff forecasts. Furthermore, the change in the frequency of intermeeting moves raises the spectre of instability in the reaction function. ${ }^{60}$ The pre-1993 inter-meeting moves are less of a concern for our quarterly models, because in these specifications the funds rate is not as closely tied to any particular meeting. So we chose to include these data points to maximize the number of observations, except when considering the proxies based on individuals' forecast distributions from the SPF. In the latter cases, the first observation is $1992 \mathrm{Q} 1$, to coincide with a discrete change in SPF methodology. ${ }^{61}$

Tables 4 and 5 display summary statistics for Federal Reserve Board staff forecasts of inflation and the output gap and the various proxies for risk management at the meeting and quarterly frequencies. What is most worth noting in these tables is that no risk proxy displays a particularly large positive or negative correlation with either the output gap or inflation forecast. This suggests that our proxies contain information that is not already incorporated into these forecasts. Nevertheless, some variables have moderately large correlations in absolute value, so the forecasts do somewhat reflect underlying risks to the outlook. Interestingly, skewness in forecasters' GDP forecasts (GDP) is negatively correlated with the outlook for activity.

Tables 6 and 7 display cross-correlations of the FOMC-based and quarterly proxies, respectively. As suggested by figures 4 and 5 , the humanand machine-coded FOMC variables for uncertainty and insurance are essentially uncorrelated. These variables also appear unrelated to the forecast revision variables. However, several correlations among the quarterly proxies are worth noting. Forecaster variance and disagreement about the GDP growth outlook (vGDP and DvGDP) are both positively correlated

60. Between 1990 and 1992, only 4 of the 18 changes in the funds rate target occurred at an FOMC meeting. In contrast, between 1993 and 2008, 54 of the 61 changes in the funds rate target occurred at FOMC meetings. Ignoring inter-meeting moves causes specification problems if interest rate smoothing is a function not only of time but also of the number of policy moves. Indeed, when we estimated our meeting frequency models starting in 1987, our point estimates were (statistically) similar, but even with 5 funds rate lags substantial serial correlation remained in the residuals.

61. In 1992 the SPF narrowed the bins it used to summarize the forecast probability distributions of individual forecasters. See D'Amico and Orphanides (2014) and Andrade, Ghysels, and Idier (2013) for attempts to address this change in bin sizes. 


\begin{tabular}{|c|c|c|c|c|c|c|c|}
\hline \multirow[b]{2}{*}{ Variable } & \multirow[b]{2}{*}{ Obs. } & \multirow[b]{2}{*}{ Mean } & \multirow[b]{2}{*}{$\begin{array}{l}\text { Standard } \\
\text { deviation }\end{array}$} & \multirow[b]{2}{*}{ Minimum } & \multirow[b]{2}{*}{ Maximum } & \multicolumn{2}{|c|}{$\begin{array}{c}\text { Correlation } \\
\text { with forecast of }\end{array}$} \\
\hline & & & & & & Inflation & $\begin{array}{l}\text { Output } \\
\text { gap }\end{array}$ \\
\hline $\begin{array}{l}\text { Inflation } \\
\text { forecast }\end{array}$ & 128 & 2.45 & 0.45 & 1.30 & 3.53 & 1.00 & 0.21 \\
\hline $\begin{array}{c}\text { Output gap } \\
\text { forecast }\end{array}$ & 128 & -0.14 & 1.58 & -4.85 & 3.08 & 0.21 & 1.00 \\
\hline hUnc & 128 & -0.13 & 0.48 & -1 & 1 & -0.23 & -0.33 \\
\hline hIns & 128 & -0.06 & 0.33 & -1 & 1 & 0.18 & 0.15 \\
\hline mUnc & 128 & 2.92 & 4.80 & 0 & 30.8 & -0.06 & 0.14 \\
\hline mIns & 128 & 0.83 & 2.45 & 0 & 16.7 & -0.10 & 0.08 \\
\hline frInf & 128 & -0.01 & 0.18 & -0.63 & 0.63 & 0.23 & 0.01 \\
\hline frGap & 128 & -0.01 & 0.41 & -2.00 & 0.77 & 0.24 & 0.29 \\
\hline
\end{tabular}

Source: Authors' calculations, based on Philadelphia Fed Greenbook data sets and FOMC minutes; see text.

Table 5. Summary Statistics for Quarterly Risk Proxies

\begin{tabular}{|c|c|c|c|c|c|c|c|}
\hline \multirow[b]{2}{*}{ Variable } & \multirow[b]{2}{*}{$\begin{array}{l}\text { Obser- } \\
\text { vations }\end{array}$} & \multirow[b]{2}{*}{ Mean } & \multirow[b]{2}{*}{$\begin{array}{l}\text { Standard } \\
\text { deviation }\end{array}$} & \multirow[b]{2}{*}{ Міпітит } & \multirow[b]{2}{*}{ Maximum } & \multicolumn{2}{|c|}{$\begin{array}{c}\text { Correlation } \\
\text { with forecasts of }\end{array}$} \\
\hline & & & & & & Inflation & $\begin{array}{l}\text { Output } \\
\text { Gap }\end{array}$ \\
\hline $\begin{array}{l}\text { Inflation } \\
\text { forecast }\end{array}$ & 86 & 2.97 & 1.02 & 1.33 & 5.32 & 1.00 & -0.04 \\
\hline $\begin{array}{c}\text { Output gap } \\
\text { forecast }\end{array}$ & 86 & -0.45 & 1.69 & -4.4 & 3.08 & -0.04 & 1.00 \\
\hline VXO & 86 & 21.0 & 8.48 & 10.6 & 62.1 & -0.02 & 0.04 \\
\hline JLN & 86 & 0.96 & 0.05 & 0.89 & 1.22 & -0.06 & -0.04 \\
\hline vInf & 68 & 0.74 & 0.06 & 0.6 & 0.90 & -0.22 & -0.08 \\
\hline vGDP & 68 & 0.9 & 0.12 & 0.67 & 1.30 & -0.22 & 0.22 \\
\hline DvInf & 86 & 0.6 & 0.18 & 0.24 & 1.10 & 0.25 & -0.35 \\
\hline DvGDP & 86 & 0.73 & 0.27 & 0.3 & 1.64 & 0.37 & -0.05 \\
\hline SPD & 86 & 2.11 & 0.65 & 1.37 & 5.60 & -0.34 & -0.34 \\
\hline sInf & 68 & 0.05 & 0.08 & -0.12 & 0.30 & 0.23 & -0.12 \\
\hline sGDP & 68 & -0.10 & 0.19 & -0.54 & 0.47 & -0.10 & -0.48 \\
\hline DsInf & 86 & 0.06 & 0.20 & -0.5 & 0.51 & 0.01 & -0.23 \\
\hline DsGDP & 86 & 0.3 & 0.27 & -0.5 & 0.90 & -0.22 & 0.21 \\
\hline
\end{tabular}

Source: Authors' calculations, based on Philadelphia Fed Greenbook data sets, Survey of Professional Forecasters, Haver Analytics, and Jurado, Ludvigson, and Ng (2015); see text.

Table 6. Cross-Correlations of FOMC-Based Risk Proxies

\begin{tabular}{lrrrrr}
\hline Variable & hUnc & hIns & mUnc & mIns & frInf \\
\hline hIns & -0.05 & & & & \\
mUnc & -0.07 & 0.02 & & & \\
mIns & -0.13 & -0.09 & 0.04 & & \\
frInf & 0.10 & 0.05 & -0.07 & 0.06 & \\
frGap & -0.11 & 0.08 & 0.05 & 0.11 & 0.25
\end{tabular}

Source: Authors' calculations, based on Philadelphia Fed Greenbook data sets and FOMC minutes; see text. 


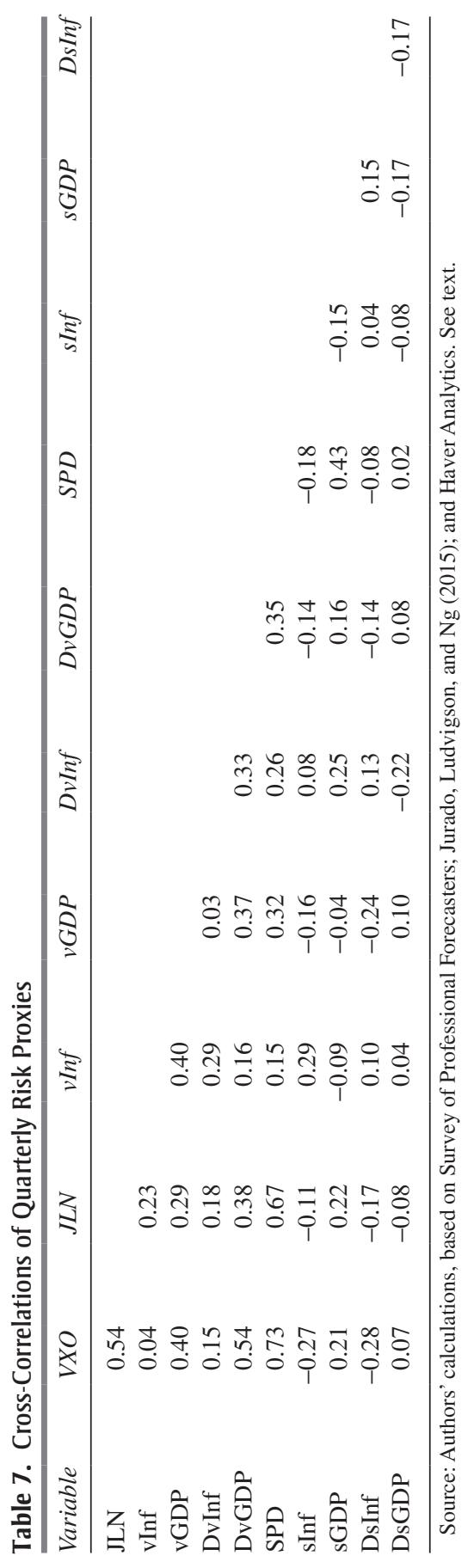


with VXO and SPD, suggesting that the financial variables do reflect some uncertainty about the growth outlook. Also, the relatively high correlation of SPD with sGDP suggests that the former to some extent captures skewness in the growth outlook. The correlation of vGDP with vInf and DvGDP with DvInf are both fairly large, suggesting that uncertainty about inflation and uncertainty about GDP often move together. The correlations of the corresponding forecaster uncertainty and disagreement variables (vGDP with DvGDP and vInf with DvInf) are somewhat large too. Evidently, the amount of disagreement among forecasters is similar to the median amount of uncertainty they see. Finally Jurado, Ludvigson, and Ng's (2015) measure of macroeconomic uncertainty, JLN, is highly correlated with VXO and SPD and to some extent with DvGDP, but much less so with any of the other risk proxies.

\section{III.B. Policy Rule Findings}

Table 8 shows our policy rule estimates with and without the various FOMC-based variables. Tables 9 and 10 show estimates with and without the quarterly variance and skewness proxies. Except for the human-coded variables $h U n c$ and $h I n s$, prior to estimation the risk proxies have been normalized to have mean zero and unit standard deviation, so their coefficients indicate percentage-point responses of the funds rate to standard deviation changes. The tables have the same layout: the first column shows the policy rule excluding any risk proxies, and the other columns show the policy rules after adding the indicated risk proxy. The coefficient associated with a given risk proxy corresponds to an estimate of $\mu$ in equation 13 . The speed of adjustment to the notional funds rate target $\left(\sum_{j=1}^{N} a_{j}\right)$ and the coefficients on the forecasts of inflation $(\beta)$ and the output gap $(\gamma)$ are similar across specifications and consistent with estimated forecast-based policy rules in the literature.

From table 8 we see that the coefficient on the human coding of uncertainty $(h U n c)$ is statistically significant at the 5 percent level, indicating that when uncertainty has shaded the policy decision above or below the forecast-only prescription it has moved the notional target by 40 basis points. With interest rate smoothing the immediate impact is much smaller; the 95 percent confidence interval is 2 to 14 basis points. The machine coding of uncertainty $(m U n c)$ is significant at the 10 percent level but the effect is small. The insurance indicators ( $h I n s$ and $m I n s$ ) are not significant, but the point estimate of the hIns coefficient is similar to its uncertainty counterpart. The coefficient on the output gap forecast revision variable (frGap) is large and significant, indicating a one-standard-deviation positive surprise 


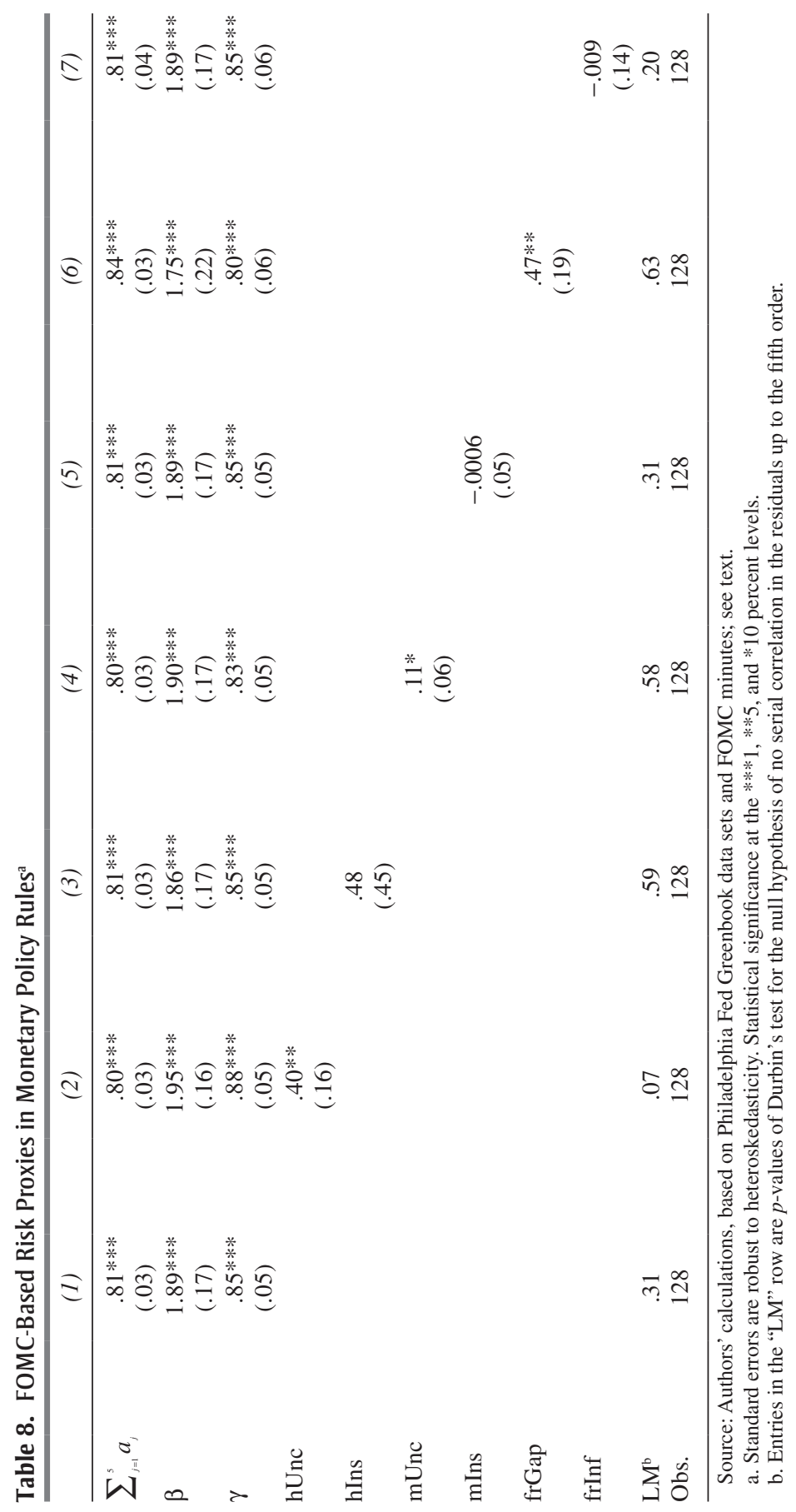


in the forecast raises the notional target by 47 basis points over and above the impact this surprise has on the forecast itself. ${ }^{62}$ In contrast, revisions to the inflation outlook (frInf) do not influence policy beyond their direct effect on the forecast.

Table 9 shows clear evidence that variance in the economic outlook has shaded policy away from the forecast-only prescription. The coefficients on VXO and JLN are both statistically and economically significant, with one-standard-deviation increases lowering the notional target funds rate by 43 and 29 basis points, respectively. ${ }^{63}$ Disagreement over the GDP forecast (DvGDP) has a significant coefficient, which is similar to the ones for VXO and JLN, suggesting that the latter variables' correlation with monetary policy reflects uncertainty in the growth outlook. That all these coefficients are negative suggests that higher uncertainty about growth has influenced the FOMC when it was concerned about recessionary dynamics and lowered the funds rate more than prescribed by the forecast alone. The only other significant coefficient in table 9 corresponds to the measure of individual forecasters' views about the uncertainty in their inflation forecasts (vInf). In this case uncertainty shades the policy higher, by about 20 basis points. This suggests that higher uncertainty about the inflation forecast has influenced the FOMC when it was concerned about inflation rising above desired levels and raised rates above levels prescribed by the baseline forecast.

Similarly strong evidence that skewness has mattered for policy decisions is found in table 10. The coefficients are significant on the interestrate-spread indicator of downside risks to activity (SPD), skewness in the outlook for inflation measured from forecasters' own forecast distributions (sInf), and skewness in the inflation outlook measured across point forecasts (DsInf). An increase in perceived downside risks to activity lowers the funds rate, while an increase in perceived upside risks to inflation raises it. The effects seem large; increases in the skewness proxies change the notional target by $-56,23$, and 40 basis points, respectively.

These findings reinforce our findings on the variance proxies and, similarly, seem consistent with our reading of FOMC communications. The

62. The magnitude and significance of this coefficient is largely driven by the sharp decline in the funds rate in 2008 that occurred alongside substantial downward revisions to the output gap forecast.

63. The JLN variable can be expressed as a linear combination of the three uncertainty measures constructed with the underlying activity, inflation, and financial indicators separately. We used Jurado, Ludvigson, and Ng's (2015) replication software to separate out these components, and found that the estimated effects of JLN are driven primarily by the financial indicators. 


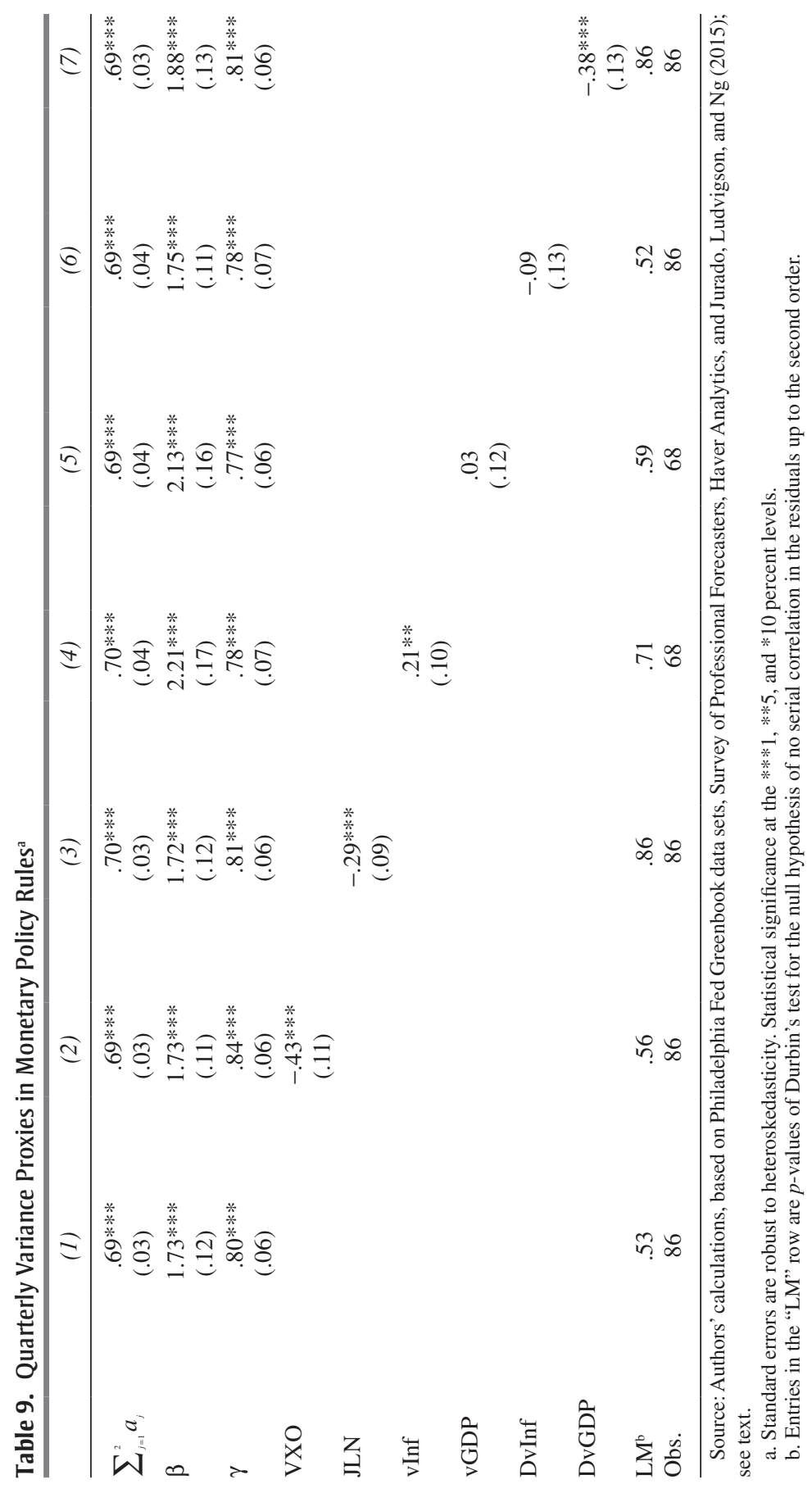


Table 10. Quarterly Skewness Proxies in Monetary Policy Rules ${ }^{\mathrm{a}}$

\begin{tabular}{|c|c|c|c|c|c|c|}
\hline & (1) & (2) & (3) & (4) & (5) & (6) \\
\hline$\sum_{j=1}^{2} a_{j}$ & $\begin{array}{l}.69^{* * *} \\
(.03)\end{array}$ & $\begin{array}{l}.68 * * * \\
(.03)\end{array}$ & $\begin{array}{l}.71 * * * \\
(.04)\end{array}$ & $\begin{array}{l}.70^{* * *} \\
(.04)\end{array}$ & $\begin{array}{l}.72 * * * \\
(.03)\end{array}$ & $\begin{array}{l}.69 * * * \\
(.03)\end{array}$ \\
\hline$\beta$ & $\begin{array}{l}1.73 * * * \\
(.12)\end{array}$ & $\begin{array}{l}1.55^{* * * *} \\
(.11)\end{array}$ & $\begin{array}{l}2.02 * * * \\
(.16)\end{array}$ & $\begin{array}{l}2.09 * * * \\
(.16)\end{array}$ & $\begin{array}{l}1.74 * * * \\
(.10)\end{array}$ & $\begin{array}{l}1.69 * * * \\
(.12)\end{array}$ \\
\hline$\gamma$ & $\begin{array}{l}.80^{* * * *} \\
(.06)\end{array}$ & $\begin{array}{l}.71 * * * \\
(.06)\end{array}$ & $\begin{array}{l}.80^{* * * *} \\
(.07)\end{array}$ & $\begin{array}{l}.74 * * * \\
(.08)\end{array}$ & $\begin{array}{l}.89^{* * * *} \\
(.08)\end{array}$ & $\begin{array}{l}.81 * * * \\
(.07)\end{array}$ \\
\hline SPD & & $\begin{array}{l}-.56 * * * \\
(.14)\end{array}$ & & & & \\
\hline sInf & & & $\begin{array}{l}.23 * * \\
(.10)\end{array}$ & & & \\
\hline sGDP & & & & $\begin{array}{l}-.15 \\
(.11)\end{array}$ & & \\
\hline DsInf & & & & & $\begin{array}{l}.40^{* * * *} \\
(.13)\end{array}$ & \\
\hline DsGDP & & & & & & $\begin{array}{l}-.16 \\
(.12)\end{array}$ \\
\hline $\mathrm{LM}^{\mathrm{b}}$ & .53 & .90 & .34 & .67 & .61 & .62 \\
\hline Obs. & 86 & 86 & 68 & 68 & 86 & 86 \\
\hline
\end{tabular}

a. Standard errors are robust to heteroskedasticity. Statistical significance at the $* * * 1$, $* * 5$, and $* 10$ percent levels.

b. Entries in the "LM" row are $p$-values of Durbin's test for the null hypothesis of no serial correlation in the residuals up to the second order.

point estimates for skewness in the GDP outlook (sGDP and DsGDP) have surprisingly negative signs. However these coefficients are relatively small and insignificant.

Taken together, these results indicate that risk management concerns, broadly conceived, have had a statistically and economically significant impact on policy decisions over and above how those concerns are reflected in point forecasts. The effects we find suggest that the FOMC acted aggressively to offset concerns about declining growth or rising inflation. We conclude from this econometric analysis that risk management does not just appear in the words of the FOMC - it is reflected in the FOMC's deeds as well.

\section{Conclusion}

We have focused on risk surrounding the forecast as a relevant consideration for monetary policy near the ZLB, but other issues are relevant to the liftoff calculus as well. In particular, policymakers may face 
large reputational costs of reversing a decision. Empirically, it is well known that central banks tend to go through "tightening" and "easing" cycles, which in turn induce substantial persistence in the short-term interest rate. Uncertainty over the outlook may be one reason for this persistence. But another reason why policymakers might be reluctant to reverse course is that doing so would damage their reputation, perhaps because the public would lose confidence in the central bank's ability to understand and stabilize the economy. With high uncertainty, this reputational element would lead to more caution. In the case of liftoff, it argues for a longer delay in raising rates to avoid the reputational costs of reverting to the ZLB.

Another reputational concern is the signal the public might infer about the central bank's commitment to its stated policy goals. With regard to liftoff, suppose it occurred with output or inflation still far below target. Large gaps on their own pose no threat to the central bank's credibility if the public is confident that the economy is on a path to achieve its objectives in a reasonable period and that it is willing to accommodate this path. However, if there is uncertainty over the strength of the economy, early liftoff might be construed as a less-than-enthusiastic endorsement of the central bank's ultimate policy objectives. Motivated by the current situation, we have focused in the paper on the case of a central bank that is undershooting its inflation target, but similar issues would arise if risk management considerations dictated an aggressive tightening to guard against inflation and the central bank failed to act accordingly. In a wide class of models, such losses of credibility can have deleterious consequences for achieving the central bank's objectives.

ACKNOWLEDGMENTS We thank numerous seminar participants and Gadi Barlevy, Jeffrey Campbell, Stefania D’Amico, Alan Greenspan, Alejandro Justiniano, John Leahy, Sydney Ludvigson, Leonardo Melosi, Taisuke Nakata, Serena Ng, Valerie Ramey, David Reifschneider, Glenn Rudebusch, Paolo Surico, François Velde, and Johannes Wieland for their help and comments; Theodore Bogusz, David Kelley and Trevor Serrao for superb research assistance; and the volume editors. We also thank Michael McMahon for providing us with machine-readable FOMC minutes and transcripts and Thomas Stark for help with the Philadelphia Fed's real-time data. The views expressed herein are those of the authors and do not necessarily represent the views of the Federal Open Market Committee or the Federal Reserve System. 


\section{References}

Adam, Klaus and Roberto M. Billi. 2007. "Discretionary Monetary Policy and the Zero Lower Bound on Nominal Interest Rates." Journal of Monetary Economics 54, no. 3: 728-52.

Alcidi, Cinzia, Alessandro Flamini, and Andrea Fracasso. 2011. "Policy Regime Changes, Judgment and Taylor Rules in the Greenspan Era." Economica 78: 89-107.

Andrade, Philippe, Eric Ghysels, and Julien Idier. 2013. "Tails of Inflation Forecasts and Tales of Monetary Policy." Kenan-Flagler Research Paper No. 201317, University of North Carolina.

Baker, Scott R., Nicholas Bloom, and Steven J. Davis. 2015. "Measuring Economic Policy Uncertainty.” Working Paper. http://www.policyuncertainty.com/ media/BakerBloomDavis.pdf

Barlevy, Gadi. 2011. "Robustness and Macroeconomic Policy." Annual Review of Economics 3: 1-24.

Barsky, Robert, Alejandro Justiniano, and Leonardo Melosi. 2014. "The Natural Rate and Its Usefulness for Monetary Policy Making." American Economic Review 104, no. 4: 37-43.

Basu, Susanto, and Brent Bundick. 2014. "Downside Risk at the Zero Lower Bound." Working Paper. http://www.cla.auburn.edu/economics/assets/File/ BasuBundickDownsideRisk.pdf

Bekaert, Geert, Marie Hoerova, and Marco Lo Duca. 2013. "Risk, Uncertainty and Monetary Policy." Journal of Monetary Economics 60: 771-88.

Bernanke, Ben S. 2012. "The Changing Policy Landscape.” In Monetary Policy since the Onset of the Crisis, Economic Policy Symposium, pp. 1-22. Kansas City: Federal Reserve Bank of Kansas City.

Bloom, Nicholas. 2009. "The Effect of Uncertainty Shocks." Econometrica 77, no. 3: 623-85.

Bomfin, A., and L. Meyer. 2010. "Quantifying the Effects of Fed Asset Purchases on Treasury Yields.” Monetary Policy Insights: Fixed Income Focus. Macroeconomics Advisors (online).

Born, Benjamin, and Johannes Pfeifer. 2014. "Policy Risk and the Business Cycle." Journal of Monetary Economics 68: 68-85.

Brainard, William. 1967. "Uncertainty and the Effectiveness of Policy." American Economic Review 57, no. 2: 411-25.

Campbell, Jeffrey R., Charles. L. Evans, Jonas D. Fisher, and Alejandro Justiniano. 2012. "Macroeconomic Effects of Federal Reserve Forward Guidance." Brookings Papers on Economic Activity, Spring, 1-54.

Castelnuovo, Efrem. 2003. "Taylor Rules, Omitted Variables, and Interest Rate Smoothing in the U.S." Economics Letters 81, no. 1: 55-59.

Chen, Han, Vasco Curida, and Andrea Ferrero. 2012. "The Macroeconomic Effects of Large Scale Asset Purchase Programmes.” Economic Journal 122, no. 564: 289-315. 
Chevapatrakul, T., T. Kim, and P. Mizen. 2009. "The Taylor Principle and Monetary Policy Approaching a Zero Bound on Nominal Rates: Quantile Regression Results for the United States and Japan.” Journal of Money, Credit and Banking 41, no. 8: $1705-23$.

Christiano, Lawrence, Martin Eichenbaum, and Charles Evans. 2005. "Nominal Rigidities and the Dynamic Effects of a Shock to Monetary Policy." Journal of Political Economy 113, no. 1: 1-45.

Clarida, Richard, Jordi Galí, and Mark Gertler. 2000. "Monetary Policy Rules and Macroeconomic Stability: Evidence and Some Theory." Quarterly Journal of Economics 115, no. 1: 147-80.

Coibion, Olivier, Yuriy Gorodnichenko, and Johannes Wieland. 2012. "The Optimal Inflation Rate in New Keynesian Models: Should Central Banks Raise Their Inflation Targets in Light of the Zero Lower Bound?" Review of Economic Studies 79, no. 4: 1371-1406.

Cúrdia, Vasco, Andrea Ferrero, Ging Cee Ng, and Andrea Tambalotti. 2015. "Has U.S. Monetary Policy Tracked the Efficient Interest Rate." Journal of Monetary Economics 70 (March): 72-83.

D'Amico, Stefania, and Thomas King. 2013. "Flow and Stock Effects of LargeScale Treasury Purchases: Evidence on the Importance of Local Supply." Journal of Financial Economics 108, no. 2: 425-448.

2015. "Policy Expectations, Term Premia, and Macroeconomic Performance." Unpublished manuscript. Chicago: Federal Reserve Bank of Chicago.

D'Amico, Stefania, and Athanasios Orphanides. 2014. "Inflation Uncertainty and Disagreement in Bond Risk Premia." Working Paper 2014-24. Chicago: Federal Reserve Bank of Chicago.

Dolado, Juan J., P. Ramón María-Dolores, and Manuel Naveira. 2005. “Are Monetary Policy Reaction Functions Asymmetric? The Role of Nonlinearity in the Phillips Curve." European Economic Review 49, no. 2: 485-503.

Dolado, Juan J., P. Ramón María-Dolores, and Francisco J. Ruge-Murcia. 2004. "Nonlinear Monetary Policy Rules: Some New Evidence for the U.S." Studies in Nonlinear Dynamics and Econometrics 8, no. 3.

Egertsson, Gauti B., and Michael Woodford. 2003. "The Zero Bound on Interest Rates and Optimal Monetary Policy." Brookings Papers on Economic Activity 2003, no. 1: 139-211.

Eichenbaum, Martin, and Jonas D. Fisher. 2007. "Estimating the Frequency of Price Re-Optimization in Calvo-Style Models." Journal of Monetary Economics 54, no. 7: 2032-47.

Engen, Eric M., Thomas T. Laubach, and David Reifschneider. 2015. "The Macroeconomic Effects of the Federal Reserve's Unconventional Monetary Policy." Finance and Economics Discussion no. 2012-5. Washington: Board of Governors of the Federal Reserve System.

English, William B., J. David Lopez-Salido, and Robert Tetlow. 2013. “The Federal Reserve's Framework for Monetary Policy—Recent Changes and New Questions." Finance and Economics Discussion no. 2013-76. Washington: Board of Governors of the Federal Reserve System. 
Evans, Charles L. 2014. "Patience Is a Virtue When Normalizing Monetary Policy." Speech presented at the Conference on Labor Market Slack, Peterson Institute for International Economics, Washington, September 24.

Fernandez-Villaverde, Jesus, Pablo Guerron-Quintana, Keith Kuester, and Juan Rubio-Ramirez. 2012. "Fiscal Volatility Shocks and Economic Activity." Working Paper no. 11-32/R. Philadelphia: Federal Reserve Bank of Philadelphia.

Friedman, Benjamin M. 1975. Economic Stabilization Policy: Methods in Optimization. Amsterdam and New York: North-Holland Publishing Company and American Elsevier Publishing Company.

Fuhrer, Jeffrey C. 2000. "Habit Formation in Consumption and Its Implications for Monetary-Policy Models." American Economic Review 90, no. 3: 367-90.

Gagnon, J., M. Raskin, J. Remache, and B. Sack. 2010. "Optimal Fiscal and Monetary Policy with Occasionally Binding Zero Bound Constraints." Staff Report no. 441. New York: Federal Reserve Bank of New York.

Galí, Jordi. 2008. An Introduction to the New Keynesian Framework. Princeton University Press.

Galí, Jordi, and Mark Gertler. 1999. "Inflation Dynamics: A Structural Econometric Analysis.” Journal of Monetary Economics 44, no. 2: 192-222.

Gerlach-Kristen, Petra. 2004. "Interest Rate Smoothing: Monetary Policy Inertia or Unobserved Variables." Contributions in Macroeconomics 4, no. 1: 1534-6005.

Gilchrist, Simon, and Egon Zakrajšek. 2012. "Credit Spreads and Business Cycle Fluctuations." American Economic Review 102, no. 4: 1692-1720.

Gnabo, Jean-Yves, and Diego N. Moccero. 2015. "Risk Management, Nonlinearity and Aggressiveness in Monetary Policy: The Case of the U.S." Journal of Banking \& Finance 55: 281-94.

Goodfriend, Marvin. 1991. "Interest Rates and the Conduct of Monetary Policy." Carnegie-Rochester Conference Series on Public Policy no. 34: 7-30.

Greenspan, Alan. 2004. "Risk and Uncertainty in Monetary Policy." American Economic Review 94, no. 2: 33-40.

Hamilton, James D., Ethan S. Harris, Jan Hatzius, and Kenneth D. West. 2015. "The Equilibrium Real Funds Rate: Past, Present and Future." Unpublished manuscript, University of California-San Diego.

Hamilton, James, and Jing Wu. 2010. "The Effectiveness of Alternative Monetary Policy Tools in a Zero Lower Bound Environment." Unpublished manuscript, University of California-San Diego.

Hansen, Lars, and Thomas Sargent. 2008. "Robustness." Princeton University Press.

Jurado, Kyle, Sydney Ludvigson, and Serena Ng. 2015. "Measuring Uncertainty." American Economic Review 105, no. 3: 1177-1276.

Kiesel, Konstantin, and Maik H. Wolters. 2014. "Estimating Monetary Policy Rules When the Zero Lower Bound on Nominal Interest Rates Is Approached." Kiel Working Paper no. 1898, Kiel Institute for the World Economy.

Kiley, Michael T. 2012. "The Aggregate Demand Effects of Short- and Long-Term Interest Rates.” Finance and Economics Discussion no. 2012-54. Washington: Board of Governors of the Federal Reserve System. 
Kilian, Lutz, and Simone Manganelli. 2008. "The Central Banker as a Risk Manager: Estimating the Federal Reserve's Preferences under Greenspan.” Journal of Money, Credit and Banking 40, no. 6: 1103-29.

Krishnamurthy, Arvind, and Annette Vissing-Jørgensen. 2013. "The Ins and Outs of LSAPS." Proceedings of the Economic Policy Symposium-Jackson Hole. Federal Reserve Bank of Kansas City.

Krugman, Paul R. 1998. "It's Baaack: Japan's Slump and the Return of the Liquidity Trap." Brookings Papers on Economic Activity, no. 2: 137-87.

Laubach, Thomas, and John C. Williams. 2003. "Measuring the Natural Rate of Interest." Review of Economics and Statistics 85. no. 4: 1063-70.

Laxton, Douglas, David Rose, and Demosthenes Tambakis. 1999. "The U.S. Phillips Curve: The Case for Asymmetry." Journal of Economic Dynamics \& Control 23, nos. 9, 10: 1459-85.

Mas-Colell, Andreau, Michael D. Whinston, and Jerry R. Green. 1995. Microeconomic Theory. Oxford University Press.

Mumtaz, Haroon, and Paolo Surico. 2015. "The Transmission Mechanism in Good and Bad Times." International Economic Review, forthcoming.

Nakata, Taisuke. 2013a. "Optimal Fiscal and Monetary Policy with Occasionally Binding Zero Bound Constraints." Finance and Economics Discussion no. 2013-40. Washington: Board of Governors of the Federal Reserve System.

. 2013b. "Uncertainty at the Zero Lower Bound." Finance and Economics Discussion no. 2013-09. Washington: Board of Governors of the Federal Reserve System.

Nakata, Taisuke, and Sebastian Schmidt. 2014. "Conservatism and Liquidity Traps." Finance and Economics Discussion no. 2014-105. Washington: Board of Governors of the Federal Reserve System.

Nakov, Anton A. 2008. "Optimal and Simple Monetary Policy Rules with Zero Floor on the Nominal Interest Rate." International Journal of Central Banking 4, no. 2: 73-127.

Orphanides, Athanasios, and John C. Williams. 2002. "Robust Monetary Policy Rules with Unknown Natural Rates." Brookings Papers on Economic Activity, Fall: 63-145.

Reifschneider, David, and John C. Williams. 2000. "Three Lessons for Monetary Policy in a Low-Inflation Era." Journal of Money, Credit, and Banking 32, no. 4: 936-66.

Romer, Christina D., and David H. Romer. 1989. "Does Monetary Policy Matter? A New Test in the Spirit of Friedman and Schwartz." In NBER Macroeconomics Annual 2005, vol. 4, ed. by O. Blanchard and S. Fischer.

Rudebusch, Glenn D. 2002. "Term Structure Evidence on Interest Rate Smoothing and Monetary Policy Inertia." Journal of Monetary Economics 49, no. 6: 1161-87.

Rudebusch, Glenn, and Lars E. Svensson. 1999. "Policy Rules for Inflation Targeting." In Monetary Policy Rules, ed. by J. B. Taylor. University of Chicago Press. 
Sack, Brian. 2000. "Does the Fed Act Gradually? A VAR Analysis.” Journal of Monetary Economics 46, no. 1: 229-56.

Smets, Frank, and Rafael Wouters. 2007. "Shocks and Frictions in U.S. Business Cycles: A Bayesian DSGE Approach.” American Economic Review 97, no. 3: 586-606.

Surico, Paolo. 2007. “The Fed's Monetary Policy Rule and U.S. Inflation: The Case of Asymmetric Preferences." Journal of Economic Dynamics \& Control 31, no. 1: 305-24.

Svensson, Lars, and Michael Woodford. 2002. "Optimal Policy with Partial Information in a Forward-Looking Model: Certainty-Equivalence Redux." Working Paper, Columbia University. http://www.columbia.edu/ mw2230/ SWCE206.pdf

2003. "Indicator Variables for Optimal Policy." Journal of Monetary Economics 50, no. 3: 691-720.

Taylor, John B. 1993. "Discretion versus Policy Rules in Practice." CarnegieRochester Conference Series on Public Policy no. 39: 195-214.

Tenreyro, Silvana, and Gregory Thwaites. 2015. "Pushing on a String: US Monetary Policy Is Less Powerful in Recessions.” Working Paper, London School of Economics and Political Science. http://personal.lse.ac.uk/tenreyro/TandT.pdf

Werning, Iván. 2012. "Managing a Liquidity Trap: Monetary and Fiscal Policy." Unpublished manuscript, Massachusetts of Technology.

Woodford, Michael. 2003. "Interest and Prices." Princeton University Press. . 2012. "The Changing Policy Landscape." In Methods of Policy Accommodation at the Interest-Rate Lower Bound, Economic Symposium (pp. 185-288). Kansas City: Federal Reserve Bank of Kansas City. 


\section{Comments and Discussion}

\section{COMMENT BY}

ALAN GREENSPAN In this paper, Charles Evans, Jonas Fisher, François Gourio, and Spencer Krane have produced an impressive formal evaluation of the procedures the Chicago Fed employs as it approaches monetary policy normalization. They have rightly chosen a risk management paradigm that, in my judgment and given our state of knowledge, is the appropriate strategy for policy development.

Effective policy rests primarily on the policymakers' ability to forecast economic outcomes. Obviously, if economic forecasts and the related monetary policy could be successfully driven wholly by a formal model, that is, a set of rules, neither discretion nor risk management would be necessary. Regrettably, that is not the case.

My major concern with current monetary policy deliberations is their adherence to models that failed to capture either the timing or the depth of the breakdown of 2008, arguably the most devastating global financial crisis ever. To be sure, the Great Depression of the 1930s was the most devastating economic collapse, but financial markets continued to function throughout that crisis. In the wake of the Lehman Brothers bankruptcy, however, many critical overnight markets ceased to function, precipitating an unprecedented global economic breakdown. Before the more recent crisis, the last time overnight trading had failed to function occurred for one day in 1907, when call money rates were bid at 125 percent with no offers (Homer and Sylla 1991, p. 340).

None of the major models, including that of the Federal Reserve, accurately anticipated the 2008 crisis. What claim do we central bankers have for policy credibility if we could not anticipate and address the most wrenching financial crisis of our lifetimes? 
LEVERAGE MATTERS In virtually all previous such crises, the presumptive cause was the collapse of a financial bubble triggering a bout of contagious serial debt default. Leading up to the crisis of 2008, nonfinancial balance sheets were in reasonably good shape, only to be upended by corrosive finance. Nonfinancial corporate equity, for example, has averaged close to 50 percent of assets, compared with finance, which has averaged a small fraction of that. We need to amend our standard forecasting models to incorporate those rare occasions when highly leveraged finance, otherwise appearing benign, morphs single defaults into a rapid and uncontrollable serial debt contagion that disables nonfinancial systems in its wake. While the default of Lehman Brothers was anticipated as a distinct possibility, central bankers, supported by the most advanced macro models, failed to foresee the carnage that was about to arise in the hours following the default announcement.

All such toxic events have almost always been preceded by a speculative bubble. And all bubbles, by definition, deflate. But not all deflating bubbles lead to serial default contagion. The collapse of the bubble that preceded the historic one-day stock market crash of October 19, 1987, barely nudged the economy. And the bubble that burst in 2000 left in its wake the shallowest recession since the end of World War II. However, monetary policymakers failed to fully grasp the implications of either the highly leveraged subprime crisis of 2008 or the 1929 broker loan collapse.

As I note in my book The Map and the Territory 2.0, the severity of the destruction caused by a bursting bubble is determined not by the type of asset that turns toxic but by the degree of leverage employed by the holders of those toxic assets. The latter condition dictates to what extent contagion becomes destabilizing. In short, debt leverage matters.

On the eve of the dot-com stock market crash of 2000, highly leveraged institutions held a relatively small share of equities, and an especially small share of technology stocks, which were the toxic asset of that bubble. Most stock was held by households (who were considerably less leveraged at that time than they became as the decade progressed) and pension funds. Their losses, while severe, were readily absorbed without contagious bankruptcies because the amount of debt held to fund equity investment was small. Accordingly, few lenders went into default, and crisis was avoided. A similar scenario played out following the crash of 1987.

One can imagine how those events would have played out if the stocks that fell sharply in 2000 (or 1987) had been held by leveraged institutions in the same proportions that mortgages and mortgage-backed securities were held in as of 2008. The U.S. economy almost certainly would have experienced a far more destabilizing scenario than in fact occurred. 
Alternatively, if mortgage-backed securities in 2008 had been held in unleveraged institutions - for example, defined-contribution pension funds (401ks) and mutual funds - as had been the case for stocks in 2000, those institutions would have suffered large losses, but bankruptcies triggered by debt defaults would have been far fewer.

It was the capital impairment on the balance sheets of financial institutions that provoked the crisis. Debt securities were the problem in 2008, but the same effect would have been experienced by the financial system had the dollar amount of losses incurred by highly leveraged financial institutions, in the wake of the collapsing housing bubble, been in equity investments rather than mortgage-backed securities.

We need to explicitly integrate bubbles, a combination of rational and nonrational intuitive human responses, and other aspects of behavioral economics into our monetary policy models. In the online appendix to this comment, I further probe the measurement of bubbles and their consequences. ${ }^{1}$ But more broadly, our policy models would be significantly reinforced by incorporating the behavioral long-term stabilities that are so evident in our data. They define the long-term equilibria to which economic activity is drawn.

THE LONG RUN Over the long run, inbred propensities of human nature are highly predictable. For example, time preference - the extent to which we discount claims to future values-is clearly a deeply embedded, invariant human propensity that has exhibited no significant trend over the millennia of recorded economic history. Interest rates (a manifestation of time preference) that merchants charged in ancient Rome, and even as far back as fifth-century B.C. Greece, exhibited levels not significantly different from rates that we've experienced in recent decades. Since its founding in 1694, the Bank of England's daily discount rate has been trendless-holding at an unwavering 5 percent for more than a century (1719 to 1822) and, with the exception of the inflation-ridden 1970s and 1980s, it has remained at 10 percent or less since 1822 .

Similarly, stock price rates of return that arbitrage with interest rates are also trendless, as are rates of return on business equity and commercial banking (figure 1). The private savings rate (households plus businesses), importantly determined by time preference, has been trendless since the latter part of the 19th century (figure 2). Even though the propensity to

1. Online appendixes to all papers in this volume may be found at the Brookings Papers web page, www.brookings.edu/bpea, under "Past Editions." 
Figure 1. Annual Measures of Return, 1869-2014

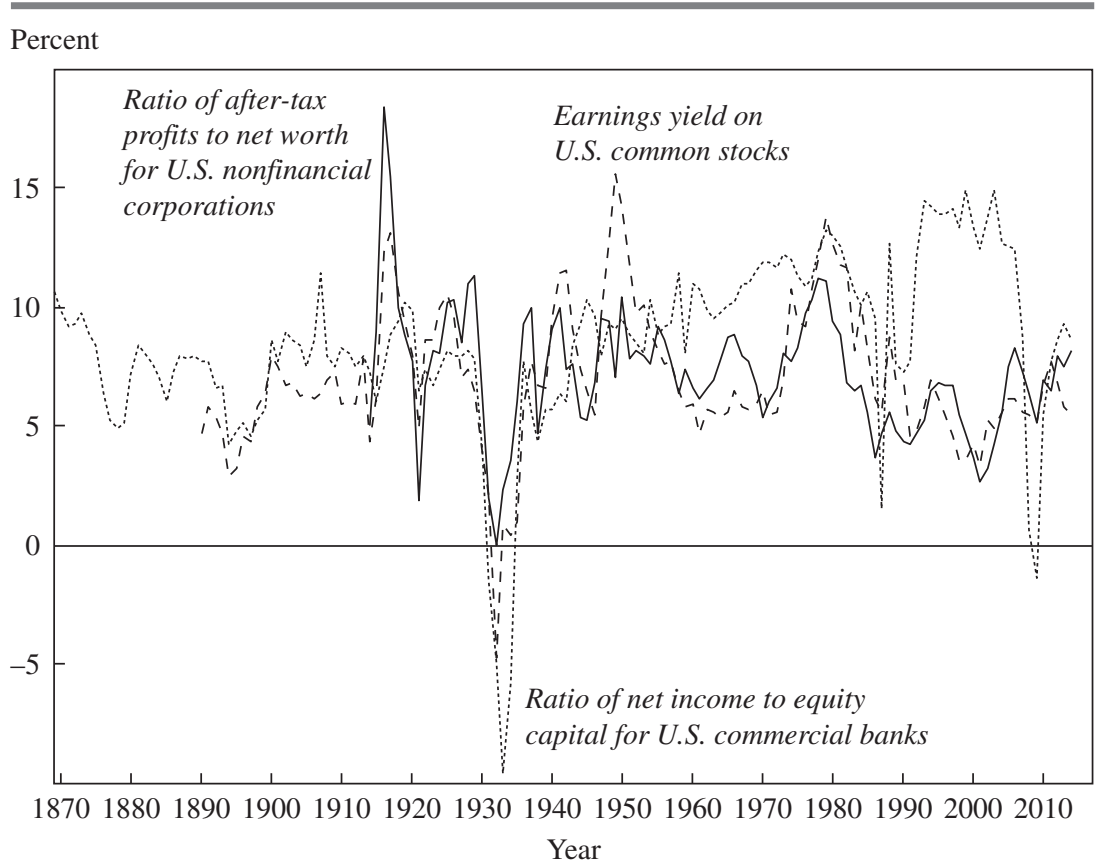

Source: Author's calculations, based on data from U.S. Federal Reserve Board, U.S. Federal Deposit Insurance Corporation, and Standard and Poor's, collected from Haver Analytics; Cowles Commission and U.S. Interstate Commerce Commission, collected from Historical Statistics of the United States, Millennial Edition.

Figure 2. Annual Gross Private Saving as a Percent of GDP, 1900-2014

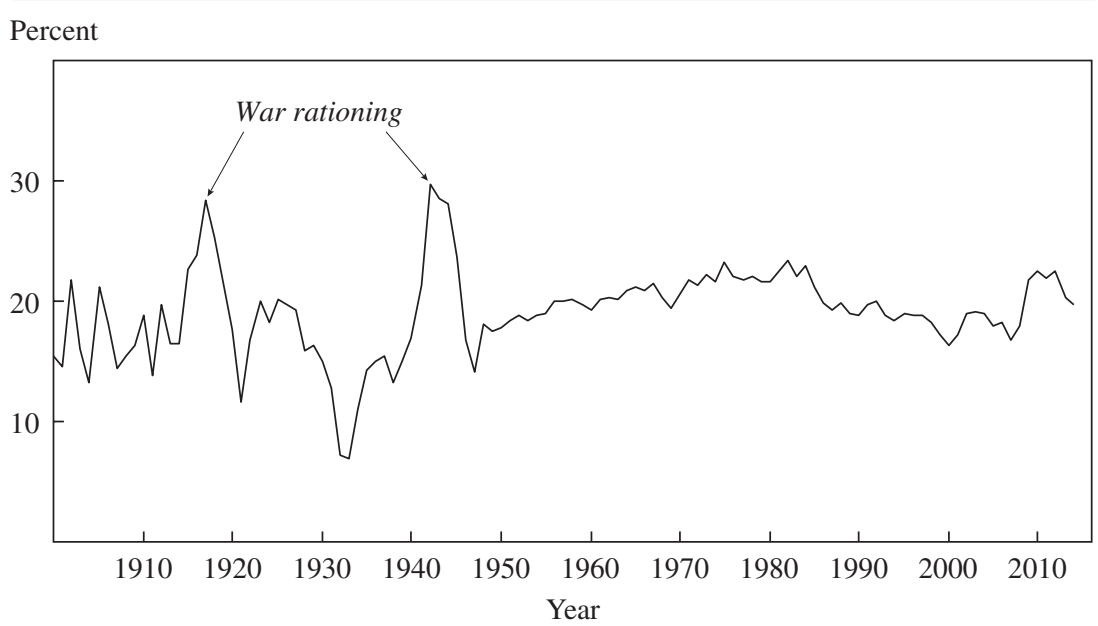

Source: Author's calculations, based on data from U.S. Bureau of Economic Analysis, collected from Haver Analytics; R. W. Goldsmith, A Study of Saving in the United States (1955), collected from Historical Statistics of the United States, Millennial Edition. 
Figure 3. Annual Capital Stock and Productivity, 1948-2013

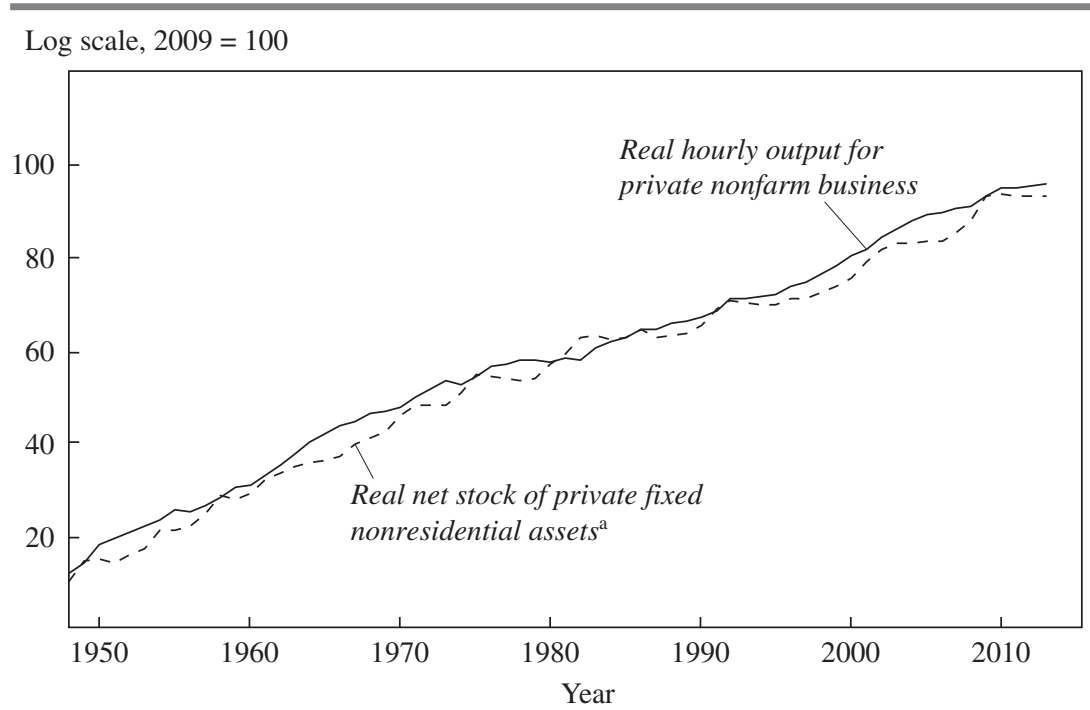

Source: Author's calculations, based on data from U.S. Bureau of Economic Analysis and U.S. Bureau of Labor Statistics, collected from Haver Analytics.

a. Measured as assets per labor hour, adjusted for quality of labor. "Quality of labor" is defined as the ratio of BLS labor inputs to hours.

save is arguably inbred, prior to the 19th century most people lived handto-mouth and were incapable of abstaining from consumption.

Savings in the form of newly produced capital goods that embody contemporaneous cutting-edge technologies are the primary sources of productivity growth. The real net business capital stock, ${ }^{2}$ adjusted to capture the increased quality of labor hours, ${ }^{3}$ closely matches the upward path of output per hour (figure 3).

Between 1870 and 1970, the United States' annual rate of increase in nonfarm output per hour (our best proxy for productivity) averaged 2.2 percent. ${ }^{4}$ Given that the accumulation of knowledge is largely irreversible, we would

2. Data published by the Bureau of Economic Analysis.

3. Data published by the Bureau of Labor Statistics.

4. My estimate for 1870 employs Angus Maddison's 1.9 percent annual rate of change between 1870 and 1913 to obtain a number consistent with the series published by John W. Kendrick and the Bureau of Labor Statistics covering the period 1889 to 2014 (see Maddison 2001). 
Figure 4. Growth in Real Hourly Output for Private Nonfarm Businesses Compared to 15 Years Prior, 1889-2014

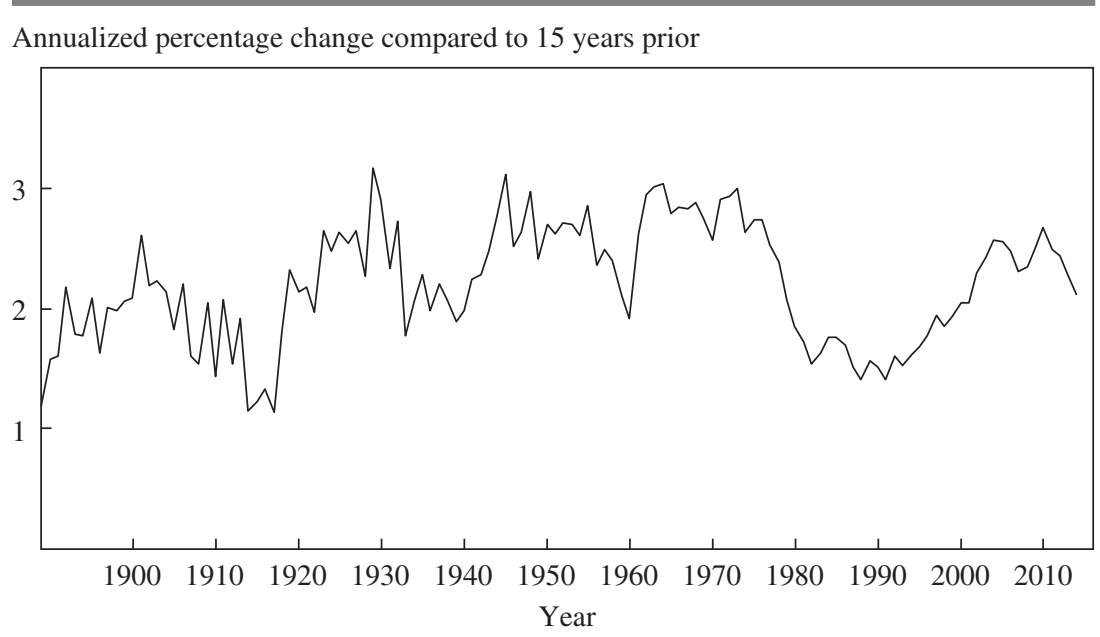

Source: Author's calculations, based on data from U.S. Bureau of Economic Analysis and U.S. Bureau of Labor Statistics, collected from Haver Analytics.

expect a persistently rising level of productivity. ${ }^{5}$ And, indeed, over any 15 -year period since 1889 , average yearly output-per-hour growth has never exceeded 3.2 percent or fallen below 1.1 percent (figure 4).

With the exception of the immediate post-World War II years, ${ }^{6}$ outputper-hour growth in most advanced economies appears to have been subject to the 3 percent growth ceiling (Maddison 2001). But why couldn't the current level of technology and productivity have been achieved in, say, 1965, rather than a half century later? I presume we human beings are not smart enough to have produced such a pace of innovation.

The relatively stable rate of growth of U.S. productivity from 1870 to 1970 doubtless reflected a combination of the long-term unchanging inbred rate of time preference (and hence savings rates) and the rate of capital stock

5. I suspect that this surprising degree of long-term stability reflects, in part, a large and slowly growing capital stock with an average age of nearly 20 years. Obviously, the greater the average age, the slower the rate of turnover and the more stable the flow of imputed "services" from that stock relative to other factors of growth. The "services" emanate daily from our capital infrastructure - our buildings, productive equipment, highways, and water systems, to identify just a few. And that relatively stable average age itself reflects the apparent stability of human time preference, a key animal spirit.

6. Virtually all war-ravaged plants and equipment in Europe were replaced with the newest technologies between 1950 and 1973. 
accumulation, coupled with the human race's inbred propensity toward optimism and competitiveness (Kahneman 2011, pp. 256-59).

Productivity growth, I presume, is capped only by the upside limit of human ability to create and apply knowledge over the long run. Certainly there is nothing to demonstrate a major difference during past millennia in the degree of intelligence of, for example, Euclid, Newton, and Einstein, the icons of outer-edge human intelligence of their respective eras. ${ }^{7}$ Although technology builds on itself, the rate of knowledge accumulation, of necessity, is limited.

THE SHORT RUN Output per hour (for business), coupled with a generally reliable increase in either the working-age population (known approximately two decades in advance) or the civilian labor force, creates a reasonable proxy for long-term growth in gross domestic product. But short-term cyclical changes require that we add equations that, at a minimum, capture both euphoria and its obverse, fear, to our dynamic stochastic general equilibrium models.

"Economic uncertainty," a widespread explanation given for much shortterm negative economic change, is more meaningfully understood in terms of relative degrees of fear. An investor increasingly uncertain of how the future will evolve becomes fearful of a significant loss of his net worth. "Uncertain" does not portray the extent of angst people experience in such circumstances. This is readily visible in figure 5 , which records the changing willingness of business managers to invest their corporations' liquid cash flow in illiquid, and hence riskier, long-term assets. Arguably, we are observing the outer ranges that business choice has exhibited over the generations and, arguably, the outer range of human euphoria and fear reflected in the marketplace (at least since 1952). But data trace trendless cycles of fear and euphoria. The upside limit, I presume, reflects an objective reality that, for example, balks at price-earnings ratios of 200. The downside limit is the extraordinary resilience of people who persevere through unimaginable stress.

We can model fixed capital expenditures as a share of cash flow by the rate at which investors discount the prospective income accruing from current capital investments in future years. One useful measure of relative fear and euphoria (uncertainty) is the yield spread between the U.S. Treasury 5 -year note and the 30 -year bond. ${ }^{8}$ This reflects the term structure of investment expectations beyond the normal business cycle length. The

7. For an interesting review of this controversial issue, see Flynn (2012).

8. Measures of credit risk are also statistically significant. 
Figure 5. Ratio of Fixed Investment to Cash Flow for Nonfinancial Corporate Businesses, 1952-2014

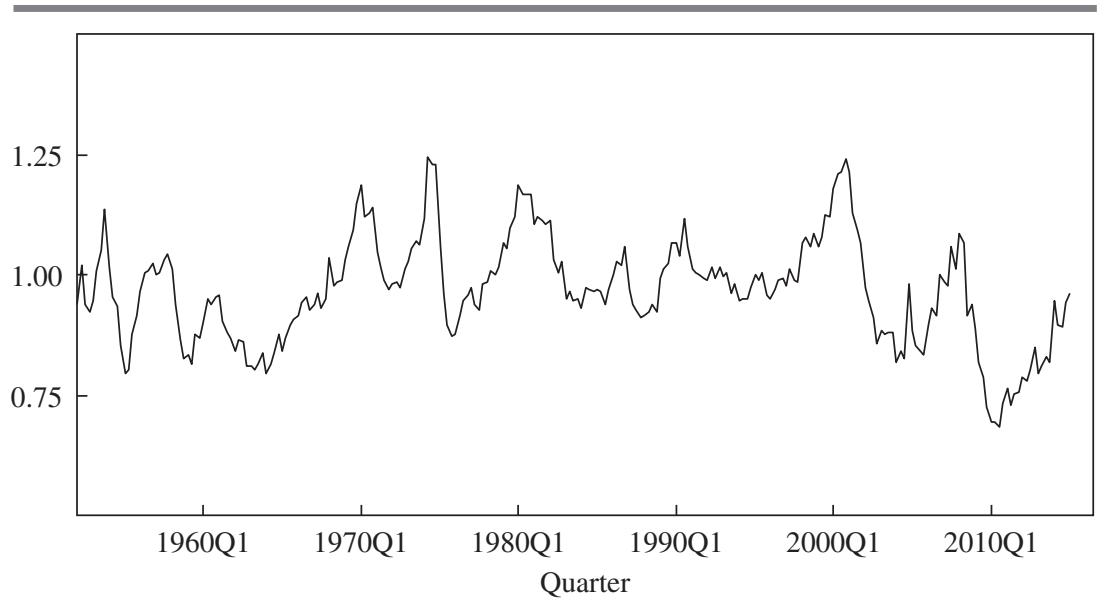

Source: Author's calculations, based on data from U.S. Federal Reserve Board, collected from Haver Analytics.

spread anticipates investment choices with a 6-month lead (figure 6). This is presumably the timing difference between decision and implementation of capital investment. In addition to the shock of the Lehman Brothers' default, the causes of such "uncertainty" are arguably global warming, the emergence of ISIS, domestic political gridlock, budget deficits, debt, taxes, and massive financial re-regulation that has weakened financial intermediation. Combined, they are engendering heavy discounting of income from long-lived investments.

UNSOLVED The one policy area I have found most challenging over the years is anticipating financial crises. Speculative stock price increases are necessarily being bolstered by an excess of bids over offers just before stock prices peak. If it were otherwise, the peak level of prices could not have been reached. But when the great preponderance of investors or speculators have shifted from "bears" to "bulls" and are presumably fully committed to a bullish future, and hence illiquid, the first market participants who wish to sell find that there are too few uncommitted cash-rich investors left to support the price level. Prices collapse into a seeming vacuum.

The timing of such a sequence is devilishly illusive. Euphoria and herding are formidable bull market human propensities. Bubbles, as history amply demonstrates, must run their course. But accurately tracing that course may, in the end, be indeterminate, since if market participants can anticipate a certain stock price peak, waves of selling will prevent that peak 
Figure 6. Log Quarterly Ratio of Fixed Investment to Cash Flow for Nonfinancial Corporate Businesses: Actual and Fitted ${ }^{a}$

Log scale

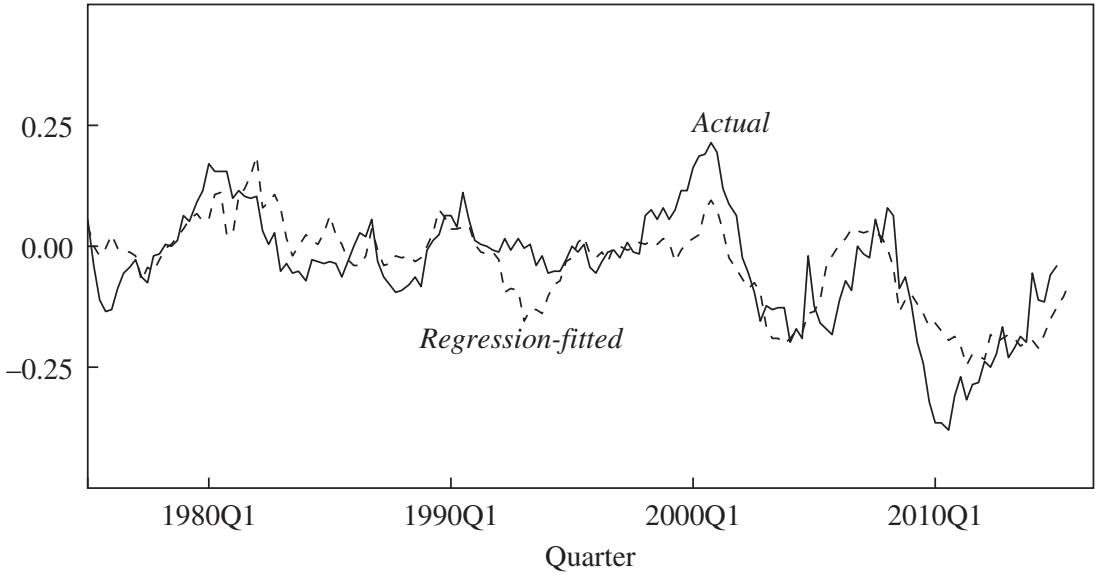

Source: Author's calculations, based on data from U.S. Federal Reserve Board, collected from Haver Analytics. a. Actual values shown through 2015Q1 and fitted values shown through 2015Q3.

\section{Regression Output for Figure 6}

Log ratio of fixed investment to cash flow

U.S. Treasury bond yield spread: $30 \mathrm{yr}-5 \mathrm{yr}^{\mathrm{b}}$

$-0.109$

$(-7.323)^{c}$

No. of observations

161

Adjusted $R^{2}$

0.590

Durbin-Watson statistic

0.348

Source: Author's calculations, based on data from U.S. Federal Reserve Board, collected from Haver Analytics.

a. For nonfinancial corporate businesses.

b. Variable is lagged two quarters, and the units are percentage points.

c. $t$-statistic calculated using Newey-West HAC standard errors and covariance.

from being reached. Indeed, for years leading up to the 2008 crisis, it was widely expected that the precipitating event of the "next" crisis would be a sharp fall in the U.S. dollar in response to the dramatic increase in the U.S. current account deficit that began in 2002. The dollar accordingly came under heavy selling pressure. The rise in the euro-dollar exchange rate from around 1.10 in the spring of 2003 to 1.30 at the end of 2004 appears to have gradually arbitraged away the presumed dollar trigger of the "next" crisis. The U.S. current account deficit did not play a prominent direct role in the timing of the 2008 crisis. 
Bubbles have always been a chronic concern of central bankers. As I noted, the bubbles of 1987 and 2000 deflated without serious economic consequence. The crises of 2008 and 1929 induced financial chaos. Those episodes, in retrospect, had the unforecastable characteristics of a snow avalanche which, in its early stages, appears benign, until it unexpectedly builds an unstoppable momentum. In short, just below the surface of an economic recession as it gets started is such an avalanche awaiting a trigger. Fortunately, the vast majority of recessions bottom out well above that triggering point, which accordingly goes unobserved as an economy turns and eventually recovers. But in very rare exceptions - 2008 being the classic case-cumulative serial default is triggered among heavily leveraged financial balance sheets and the bottom falls out of those markets, precipitating a collapse in nonfinancial activity as well.

Traditional economics has always been acutely aware of bubbles that, in large part, are driven by what Keynes labeled "animal spirits," even though these bubbles are rarely, if ever, captured in dynamic stochastic general equilibrium models. ${ }^{9}$ To be sure, we have very few observations of major bubbles in the United States-four, in all, during the past eight decades. Given what data we have, the animal spirit component of bubbles does appear to be subject to formal analysis. The behavior of stock prices is an obvious representative example.

\section{REFERENCES FOR THE GREENSPAN COMMENT}

Flynn, James R. 2012. Are We Getting Smarter? Rising IQ in the Twenty-First Century. Cambridge University Press.

Greenspan, Alan. 2014. The Map and the Territory 2.0: Risk, Human Nature, and the Future of Forecasting. New York: Penguin Books.

Historical Statistics of the United States, Millennial Edition. 2006. Cambridge University Press.

Homer, Sidney, and Richard Sylla. 1991. A History of Interest Rates, 3rd ed. Rutgers University Press.

Kahneman, Daniel. 2011. Thinking, Fast and Slow. New York: Farrar, Strauss and Giroux.

Maddison, Angus. 2001. The World Economy: A Millennial Perspective. Issy-lesMoulineaux, France: Development Centre of the Organisation for Economic Co-operation and Development.

9. To gain some statistical insight into bubbles, in the online appendix to this comment I trace out trends in daily stock price changes since 1951 and discuss the relative roles of rational judgment versus animal spirits. 


\section{COMMENT BY}

JOHANNES WIELAND Charles Evans, Jonas Fisher, François Gourio, and Spencer Krane argue in this paper that when we are uncertain over whether the zero lower bound (ZLB) will bind in the future, the prudent policy action is to be cautious about raising interest rates. This can be read as a warning that tightening now may cause a repeat of the "mistake of 1937." Then as now, the recovery from a deep recession was under way, and policymakers debated over the appropriate actions given uncertainty about the evolution of future inflation and unemployment. In fact, prominent economists have argued that premature tightening in 1937 contributed to the 1937-38 recession (Friedman and Schwartz 1963; Eggertsson and Pugsley 2006; Romer 2009).

This paper makes its case in two steps. First, the authors conduct a theoretical analysis of optimal policy under uncertainty. They show that optimal policy is looser when there is uncertainty over whether the ZLB constraint on nominal interest rates will bind. Second, they provide narrative and statistical evidence that the Federal Reserve has conducted risk management in the past, so that delaying interest rate hikes would not constitute a radical policy change. I will follow this structure and discuss each part in turn.

OPTIMAL POLICY The authors first consider the standard forward-looking new Keynesian model,

$$
\begin{gathered}
\pi_{t}=\beta \mathbb{E} \pi_{t+1}+\kappa x_{t} \\
x_{t}=\mathbb{E} x_{t+1}-\frac{1}{\sigma}\left(i_{t}-\mathbb{E} \pi_{t+1}-\rho_{t}\right),
\end{gathered}
$$

where $\pi_{t}$ is inflation, $x_{t}$ is the output gap, and $\rho_{t}$ the exogenous natural rate of interest. The central bank conducts optimal monetary policy under discretion, so each period minimizes the loss

$$
\min _{i_{i}} \frac{1}{2}\left[\pi_{t}^{2}+\lambda x_{t}^{2}\right] \quad \text { s.t. } i_{t} \geq 0
$$

For $t \geq 2$ the natural rate of interest is positive, so the central bank can perfectly stabilize the economy, $x_{t}=\pi_{t}=0$. At time $t=0$ there is uncertainty over whether the ZLB will bind at time $t=1$. For high realizations of 
the natural rate of interest (drawn from $\rho_{1} \sim f(\rho)$ ), the ZLB will not bind, whereas for low realizations it will. Thus,

$$
\begin{array}{ll}
\rho_{1} \geq 0 \Rightarrow \text { ZLB not binding: } & i_{1}>0, x_{1}=0, \pi_{1}=0, \text { and } \\
\rho_{1}<0 \Rightarrow \text { ZLB binding: } & i_{1}=0, x_{1}<0, \pi_{1}<0 .
\end{array}
$$

Since the central bank can perfectly stabilize the economy only in the first case, on average agents in this economy will expect a recession at $t=1$, $\mathbb{E}_{0} x_{1}<0, \mathbb{E}_{0} \pi_{1}<0$. Through the expectations channel, this reduces the current output gap and inflation, which the central bank wants to offset by lowering nominal interest rates today.

While risk over the ZLB constraint affects policy in this scenario, I would not label this outcome "risk management." The central bank keeps interest rates low today, because conditions today are bad (through the expectations channel) and it only cares about current outcomes. When conditions improve, this central bank will immediately raise nominal interest rates. In this scenario, there is no notion of delayed liftoff under which interest rates would be kept low despite improvements in current fundamentals. Thus, in my view, this channel does not capture the idea of risk management.

I believe the "buffer-stock" channel better captures a risk-management motive. This channel operates when there are backward-looking elements in the model, such as in the baseline old Keynesian model considered by the authors,

$$
\begin{gathered}
\pi_{t}=\xi \pi_{t-1}+\kappa x_{t} \\
x_{t}=\delta x_{t-1}+\frac{1}{\sigma}\left(i_{t}-\pi_{t-1}-\rho_{t}\right) .
\end{gathered}
$$

Again, a discretionary policymaker will minimize the expected loss:

$$
\min _{\left\{i_{t+s}\right\}} \frac{1}{2} \mathbb{E} \sum_{s=0}^{\infty}\left[\pi_{t+s}^{2}+\lambda x_{t+s}^{2}\right] \quad \text { s.t. } i_{t+s} \geq 0, \forall s \geq 0 .
$$

In contrast to the forward-looking model, the central bank's current policy will affect future inflation and output through the backward-looking structure. This gives the central bank the ability to use current policy to affect the probability and severity of future ZLB episodes even without commitment technology. 
As before, the central bank faces uncertainty over whether the ZLB binds at $t=1, \rho_{1} \sim f(\rho)$. Depending on the realization of $\rho_{1}$, the ZLB will either not be binding or will be binding at $t=1$ :

$\rho_{1} \geq \rho^{*} \Rightarrow$ ZLB not binding: $\quad i_{1}>0, x_{1}=f\left(\pi_{0}\right), \quad \pi_{1}=g\left(\pi_{0}\right)$.

$\rho_{1}<\rho^{*} \Rightarrow$ ZLB binding: $\quad i_{1}=0, x_{1}<\tilde{f}\left(\pi_{+}, \rho_{+}\right)<0, \pi_{1}=\tilde{g}\left(\pi_{+}, \rho_{+}\right)<0$.

Stimulating the economy today has clear benefits in case the ZLB does bind tomorrow. A higher output gap $x_{0}$ and inflation $\pi_{0}$ today directly raise the future output gap $x_{1}$ and inflation $\pi_{1}$ and further stimulate by lowering the real interest rate $\left.R_{1}\right|_{Z L B}=i_{1}-\pi_{0}=-\pi_{0}$. Since the economy suffers from too low output and inflation at the ZLB, such a policy would improve outcomes in that state.

However, the benefits in the ZLB states have to be balanced with the costs that occur when the ZLB does not bind. In those states, the central bank raises the real interest rate when inflation is higher so that output contracts. Thus, the more the central bank stimulates the economy today, the more the output gap and inflation deviate from target at $t=1$ if the ZLB does not bind, which reduces the payoffs in these states.

Optimal policy trades off the benefits of looser policy in the ZLB states with the costs in non-ZLB states. These are clear insurance motives, with payoffs in one state being traded off with those in another state in line with the risk-management rhetoric. Further, these motives are at play even if current economic conditions call for higher nominal interest rates. The bufferstock channel thus also provides a rationalization for delayed liftoff. ${ }^{1}$

The paper calibrates these simple models to assess the quantitative relevance of each channel. I will focus my discussion on the backward-looking channel, which I view as the more compelling theory of risk management. The two key aspects that determine the extent of risk management used are (i) how uncertain the natural rate is and (ii) how costly it is for the central bank to use the buffer-stock channel.

The one-quarter-ahead standard deviation of the annualized natural rate is set to 1.3 percent, with an unconditional standard deviation of 2.5 percent. The optimal real interest inherits the same volatility. The

1. Importantly, the policy considered here is a temporary increase in inflation. In these models, permanent increases in inflation beyond 2 percent are typically not optimal because the cost of higher inflation has to be paid every period, while the benefits only accrue when the ZLB binds (Coibion, Gorodnichenko, and Wieland 2012). 
actual ex ante real federal funds rate ${ }^{2}$ has a one-quarter-ahead standard deviation of 0.5 percent and an unconditional standard deviation of 1.61 percent from the first quarter of 1986 until the third quarter of 2008. If the estimates for the natural rate are correct, then the optimal policy must be substantially more volatile than it is in practice (this is the position taken, for example, in Barsky, Justiniano, and Melosi 2014). However, the Great Moderation is typically not associated with large output gaps, suggesting that monetary policy was not far from the natural rate. These conflicting accounts should be sorted out in another paper, but the problem leaves me concerned that the volatility of the natural rate in the calibration may be too high.

The buffer-stock channel benefits from a high persistence of inflation, which is calibrated at 0.95 in the paper. Thus, any buffer of inflation built up today will still be largely present tomorrow to help with the ZLB constraint. But empirical estimates of the backward-looking elements in Phillips curves range from 0 to 0.5 when forward-looking elements are also included (for example, as in Galí and Gertler 1999; Cogley and Sbordone 2008). The decline in persistence would make risk management more costly, since the central bank would have to create more (costly) inflation today to raise inflation tomorrow by the same amount. The forward-looking elements might help raise inflation in the ZLB states, but only if the central bank creates more (costly) inflation in future non-ZLB states. Thus, I conjecture that a more realistic specification of the Phillips curve would reduce the scope for risk management.

Another practical impediment to the buffer-stock channel is the impact lags of monetary policy. Neither narrative- nor VAR-identified monetary shocks affect inflation for several quarters (Romer and Romer 2004; Christiano, Eichenbaum, and Evans 2005; Coibion 2012). Again, I conjecture that this would make it more difficult to use the buffer-stock channel.

In short, the calibration exercise is a useful first step, but further work is needed to assess the quantitative importance of the buffer-stock channel. For example, additional real rigidities in a medium-scale model may be able to compensate for lower volatility in the natural rate and weaker inflation persistence. Further, a comparison of the buffer-stock channel with optimal policy under commitment, our existing justification for delayed

2. Calculated as the quarterly average of the federal funds rate minus expected inflation over the next quarter from the Survey of Professional Forecasters. 
liftoff (Eggertsson and Woodford 2003; Werning 2012), would be helpful to determine their relative importance.

RISK MANAGEMENT The second part of the paper focuses on whether riskmanagement considerations have affected Federal Reserve policies in the past. First, the authors search Federal Open Market Committee (FOMC) transcripts for incidents when uncertainty or insurance motives have affected policy. This in itself is a very ambitious and difficult task, since risk management motives have to be separated from first-moment shocks (such as fundamental shocks and news). For example, the following quote from minutes of the November 6, 2001, FOMC meeting, which the authors cite, suggests both first-moment news ("economic weakness had intensified") and risk-management considerations:

... members stressed the absence of evidence that the economy was beginning to stabilize and some commented that indications of economic weakness had in fact intensified. Moreover, it was likely in the view of these members that core inflation, which was already modest, would decelerate further. In these circumstances insufficient monetary policy stimulus would risk a more extended contraction of the economy and possibly even downward pressures on prices that could be difficult to counter with the current federal funds rate already quite low. Should the economy display unanticipated strength in the near term, the emerging need for a tightening action would be a highly welcome development that could be readily accommodated in a timely manner to forestall any potential pickup in inflation.

The narrative accounts reveal that uncertainty and insurance motives sometimes decrease and sometimes increase policy rates. (See the authors' figures 4 and 5). This suggests that uncertainty and insurance are not one-dimensional objects. Indeed, the transcripts show different forms of uncertainty, such as the effects of an exogenous shock and signal extraction problems. An interesting next step would be to analyze how policy responses differ for different types of uncertainty or states of the economy.

To test for the importance of risk management, the authors estimate an augmented interest rate rule,

$$
R_{t}=A(L) R_{t-1}+(1-A(1))\left[R^{*}+\beta \mathbb{E}_{t}\left(\pi_{t, k}\right)+\gamma \mathbb{E}_{t}\left(x_{t, q}\right)+\mu s_{t}\right],
$$

where $R_{t}$ is the federal funds rate, $A(L)$ a lagged polynomial, $\mathbb{E}_{t} \pi_{t, k}$ is expected inflation, $\mathbb{E}_{t} x_{t, q}$ is the expected output gap, and $s_{t}$ is an uncertainty measure. The measures used are the narratively identified insurance 
and uncertainty variables, FOMC sentence counts of uncertainty and insurance, FOMC inflation and output forecast revisions, financial uncertainty measures, and uncertainty and disagreement among professional forecasters.

Some of these measures will capture uncertainty better than others. For instance, uncertainty among professional forecasters seems to be a good measure. By contrast, the level of forecast revisions does not look like a convincing proxy to me. It would imply that positive and negative revisions have opposite implications for uncertainty. Perhaps using absolute (or squared) revisions over a rolling window would better capture forecast uncertainty.

It is also important to emphasize that the test $\mu=0$ is not a general test of whether uncertainty matters. For example, the expectations channel operates through the mean forecasts of inflation and output, which are used as controls. Thus, there is nothing left to be explained by the uncertainty proxy.

Further, only the human-coded uncertainty measure takes into account that uncertainty can affect policy both ways. For all other measures, higher uncertainty is restricted to either raising the federal funds rate (if $\mu>0$ ) or lowering the federal funds rate (if $\mu<0$ ). But if these other measures can also affect policy both ways, then the coefficient $\mu$ in the estimation is biased toward zero.

To illustrate this, I have created a new uncertainty variable, |Human Uncertaintyl, which is the absolute value of the narrative Human Uncertainty variable in the paper. It discards the information on whether uncertainty raises or lowers the policy rates and only captures whether uncertainty has affected policy. The estimates of $\mu$ for these two variables differ significantly, as shown in columns 2 and 3 of my table 1 . Only the original human-coded uncertainty measure is significant and economically important. Discarding the additional information on the policy response reduces the coefficient on $\mu$, switches its sign, and raises the standard error. Thus, by testing for unidirectional effects, we may underestimate the extent of risk management in the policy rule.

In my view, this example also illustrates that we want more measures that take into account the multidimensional aspects of uncertainty. A complementary way to proceed is to use economic theory to understand why uncertainty may sometimes cut one way and sometimes the other. For instance, uncertainty about inflation may affect policy very differently when initial current inflation is high than when current inflation is low. 
Table 1. Uncertainty Measure Using and Discarding Narrative Information

\begin{tabular}{lccc}
\hline & $(1)$ & $(2)$ & $(3)$ \\
\hline$E_{t} \mathrm{p}_{t+h}$ & $1.77^{* * *}$ & $1.95^{* * *}$ & $1.91 * * *$ \\
$E_{t} x_{t+k}$ & $(.11)$ & $(.16)$ & $(.17)$ \\
& $.79^{* * *}$ & $.88^{* * *}$ & $.86^{* * *}$ \\
Human Uncertainty & $(.06)$ & $(.05)$ & $(.06)$ \\
& & $.40 * * *$ & \\
I Human Uncertainty | & & $(.16)$ & -0.15 \\
No. of observations & 167 & & $(.19)$ \\
$R^{2}$ & 0.99 & 128 & 0.98 \\
\hline
\end{tabular}

Note: Statistical significance indicated at the $* * * 1$ percent level.

I will close by reemphasizing that this is an ambitious paper on the conduct of monetary policy under uncertainty and an important contribution to the current policy debate.

\section{REFERENCES FOR THE WIELAND COMMENT}

Barsky, Robert, Alejandro Justiniano, and Leonardo Melosi. 2014. "The Natural Rate of Interest and Its Usefulness for Monetary Policy." American Economic Review 104, no. 5: 37-43.

Christiano, Lawrence J., Martin Eichenbaum, and Charles L. Evans. 2005. "Nominal Rigidities and the Dynamic Effects of a Shock to Monetary Policy." Journal of Political Economy 113, no. 1: 1-45.

Cogley, Timothy, and Argia M. Sbordone. 2008. "Trend Inflation, Indexation, and Inflation Persistence in the New Keynesian Phillips Curve." American Economic Review 98, no. 5: 2101-26.

Coibion, Olivier. 2012. "Are the Effects of Monetary Policy Shocks Big or Small?" American Economic Journal: Macroeconomics 4, no. 2: 1-32.

Coibion, Olivier, Yuriy Gorodnichenko, and Johannes Wieland. 2012. "The Optimal Inflation Rate in New Keynesian Models: Should Central Banks Raise Their Inflation Targets in Light of the Zero Lower Bound?" Review of Economic Studies 79, no. 4: 1371-1406.

Eggertsson, Gauti B., and Benjamin Pugsley. 2006. "The Mistake of 1937: A General Equilibrium Analysis." Monetary and Economic Studies 24, no. S-1: $151-90$.

Eggertsson, Gauti B., and Michael Woodford. 2003. "The Zero Bound on Interest Rates and Optimal Monetary Policy." Brookings Papers on Economic Activity no. 1: 139-211.

Friedman, Milton, and Anna Jacobson Schwartz. 1963. A Monetary History of the United States, 1867-1960. Princeton University Press. 
Galí, Jordi, and Mark Gertler. 1999. "Inflation Dynamics: A Structural Econometric Analysis." Journal of Monetary Economics 44, no. 2: 195-222.

Romer, Christina. 2009. “The Lessons of 1937.” Economist, June 20.

Romer, Christina H., and David D. Romer. 2004. "A New Measure of Monetary Shocks: Derivation and Implications." American Economic Review 94, no. 4: 1055-84.

Werning, Iván. 2012. "Managing a Liquidity Trap: Monetary and Fiscal Policy." Working Paper. Cambridge, Mass.: Massachusetts Institute of Technology. http://economics.mit.edu/files/7558

GENERAL DISCUSSION Lars Svensson opened the conversation by complimenting the paper for its robust result that the nonlinearity of the effective lower bound justifies looser monetary policy to avoid the risk of the lower bound binding. He also felt it was time to stop using the term "zero lower bound," because the lower bound is not zero but negative, and it is not hard but soft. He would prefer to call it the effective lower bound. He noted that interest rates can become somewhat negative without huge amounts of cash being stored, because the storage cost-including insurance and crime-prevention cost—make the actual return on cash somewhat negative. Svensson found it satisfying to see another demonstration of how imperfect the Taylor Rule is, with its reliance on a symmetric response to only two variables, inflation and output. Good policy sometimes requires asymmetric responses and always requires responses to more variables than inflation and output, indeed responses to all variables that substantially affect the forecast of inflation and employment.

Donald Kohn agreed with the authors that a central bank ought to be cautious about tightening too soon when the rate is at or near the zero lower bound. He said that to some extent, what had driven him and his colleagues on the Federal Reserve Board was nonlinearity due both to deflation and approaching the zero lower bound. He himself was influenced by Japan and how it had become stuck at the zero lower bound. Kohn was surprised that discussant Alan Greenspan did not mention the "fire break" Greenspan had publicly discussed as chairman of the Federal Reserve Board in June 2003. At that time, inflation was very low, and the Federal Reserve was not planning to tighten any time soon, importantly to create a "firebreak" between the U.S. economy and deflation. Within the next year the FOMC did engage in some tightening, though very slowly, because inflation and nominal rates were still quite low. Kohn thought that had been a good example of genuine risk management. He also noted that there were interactions between interest rates at zero and financial stability that needed 
to be addressed; waiting to exit, as the authors argued, could require exiting steeply later. It seemed to him that this might threaten financial stability by taking many people by surprise.

Olivier Blanchard concurred with Kohn that the management of risk to financial stability was important and said he had expected the paper to focus on that. Even though the literature on the effect of low interest rates on creating financial risk is very unclear, some analysts believe low interest rates do create financial risks, and if they are right it would argue for the opposite of the authors' conclusion. Apart from that, Blanchard added, if there were no zero lower bound constraint, there would be no asymmetry, which raises another question: What is the optimal rate of inflation?

Andrew Levin fundamentally agreed with the authors' conclusions but also wanted to urge an attitude of humility. The FOMC and professional forecasters generally have been over-optimistic for a number of years in a row, he noted, and that means the models everyone has been using do not satisfactorily explain what is happening in the economy. The Taylor Rule is one such model and in Levin's view not adequate for deciding when to lift off again from the zero bound. New, more robust benchmarks are needed, and although this paper is an exception, policymakers have spent little effort developing them.

Judging uncertainty and risk is difficult, Levin added, as illustrated by the FOMC statement made in September 2008 just as Lehman and AIG were collapsing. The statement then only acknowledged the Fed's general concern that inflation was carrying an upside risk and that growth was carrying a downside risk. In retrospect the downside risk of overheated growth dramatically swamped any inflation risk, yet even at that moment it was hard for the FOMC to understand the magnitude of what was starting to happen.

Michael Kiley thought the paper's conclusions about policy were close to what the textbooks say one ought to do. If unemployment is above the target, textbook optimal policy says inflation should also be above the target. The paper's authors tie themselves to the model and a notion of optimal policy under discretion in the absence of the zero lower bound by defining the natural rate of interest as the shock in the IS curve and optimal policy as the nominal interest rate path that tracks this natural rate. The paper's results are clear, but by limiting the definition of optimal policy to the discretionary case in the absence of a zero lower bound, they are not as productive for future discussions as they could be. In particular, focusing on the first-order conditions would be more transparent. Emphasis on the 
discretionary case also raises additional issues: In the discretionary case, in which the FOMC is unable to commit itself, all the FOMC can do over the long run to minimize risks associated with the zero lower bound is raise its inflation target. As Michael Woodford emphasized in his discussion of an earlier Brookings paper by John Williams, there may be sizable losses associated with a higher inflation target, and these social losses may rise rapidly with the target rate of inflation. The commitment policy would give us a route that avoids such costs, and targets the price level, which would be much more efficient.

Ben Friedman thought the paper made two very important points. First, it reminds us that not all undesired outcomes are equally costly. He agreed with Johannes Wieland that when the costs are asymmetrical, with greater cost to downside rather than upside mistakes, the right choice is always to ease monetary policy because of increased uncertainty. When all of the undesired potential outcomes are not equally costly, asymmetry in the costliness of possible outcomes leads to downward bias in the optimal policy interest rate. Second, he added, the paper usefully shows that this kind of asymmetry has always been a part of actual monetary policy decisionmaking, in contrast to today's academic literature which mostly assumes quadratic loss functions and normally distributed uncertainty and therefore leaves out asymmetry altogether.

Justin Wolfers agreed with Friedman that the paper's insights are valuable, because in modern macroeconomics the models insist on optimizing everything according to rational, forward-looking decisions in ways that few people in the actual economy follow because of the asymmetries. Some people believe the unemployment rate understates the amount of economic slack and others think it is roughly correct, but no one believes the rate overstates the slack. Likewise, there is a risk that hysteresis effects are real, so if the Fed lifts off from the zero rate too early a whole generation could find itself out of work. Wolfers believed an element missing from the paper was the biases in the Fed's decisionmaking, such as its habit of always continuing to raise rates once it first raises them. One of the risks of liftoff then might be this unwillingness to retrace a step, which can lead to bad decisions down the road.

David Romer noted that a premise of the paper is that the Fed does not feel constrained in its rate setting other than the zero lower bound. But as Wolfers just pointed out, it is presuming a lot to think that once the Fed has started to raise rates, if the economy is hit with bad shocks it will have no trouble reducing rates again. That is, it seemed to Romer that once the Fed starts to tighten, the barrier to cutting rates will be higher than 
the barrier to raising them further. A second premise in the paper that gave him pause was the notion that if the Fed delays liftoff and then inflation rises faster than expected, it will have no trouble raising rates quickly. This struck him as a laudable sentiment, but in fact the Fed has not responded that way to such situations in a long time.

Martin Baily also agreed with the paper's conclusions but wanted to raise some possible counterarguments. For example, the paper assumes one can get inflation under control relatively easily, but if that were true why were so many of the Brookings Panel papers in the 1970s and 1980s devoted to solving the problem of inflation? A second counterargument echoed Blanchard's point, namely that problems might be created by keeping rates low for a very long time, especially in financial markets.

Chris Carroll noted that much of the paper's logic has echoes in the consumption literature. Even if people have quadratic utility, he said, if they see a chance of a binding constraint in the future it can induce a motive to accumulate a buffer stock of savings as a precaution. He believes this paper's argument is the extension of that insight into the monetary policy context. He then pointed out that the asymmetry that the authors highlight would be further strengthened if the model were extended to take into account the likelihood that periods when deflation looms tend to be periods when other kinds of uncertainty arise beyond the difficulty of cutting rates further. Many households are likely to feel uncertain about the future path of the economy. Such reactions would only make the asymmetric loss function much more asymmetric. The paper's argument, then, might be even stronger than the authors realize once such effects are factored in.

Johannes Wieland interjected that others might be interested in a paper he coauthored in 2012 with Olivier Coibion and Yuriy Gorodnichenko that appeared in 2012 in the Review of Economic Studies. They found that the current inflation targets are optimal in these kinds of models, and the basic idea is that when you have a temporary problem, like a zero bound, then using a permanent policy change, like raising the inflation target, is really not a well designed way to deal with it.

Julia Coronado wondered how the authors treated past errors in the model as well as in their own empirical view. The Fed has not hit its target for the better part of three decades, and optimization is always explained through a current projection starting "from now," with a promise of hitting the target at the end of an unspecified horizon. She asked whether they worried that such projections feed into expectations that in turn become a headwind, making it harder to meet the target. The prescription of simply raising the inflation target raises another credibility problem, too. 
Wendy Edelberg asked what the authors thought about what their conclusion means for average monetary policy over the long run, that is, when GDP has gotten back to its potential level but some baseline uncertainty remains. Would the natural rate of interest be so low by then that the zero lower bound would hold periodically? And is it possible that monetary policy will therefore be looser, on average, over time?

Charles Evans responded, first, to the idea that very low interest rates can trigger financial instability. He said such a relationship is very difficult to assess. The authors' intent was to take up the challenge from the editors and make the case for being more cautious about raising policy rates given uncertainty about the natural rate of interest. He has no doubt that much work can be done to better investigate the potential linkages between such policies and financial instability, and would appreciate seeing others formulate detailed arguments that could be tested empirically. But in Evans's current view, there are tools other than interest rate policy that one could use to minimize financial instability risk, including macro- and micro-prudential measures such as higher capital standards.

As for a higher inflation objective, which Blanchard and others asked about, Evans acknowledged there is an argument for such a change to give the Fed more headroom against policy running into the zero lower bound. However, he believed ample space could be achieved by the FOMC's demonstrating commitment to its stated long-run strategy of achieving a symmetric 2 percent inflation objective, one in which inflation ought to be above 2 percent half of the time and below it half of the time. He thought that if the Fed is properly symmetric in its approach, and if it responds ahead of time to economic developments, then its current 2 percent inflation objective is manageable against the constraints posed by the zero lower bound. In fact, though, over the last 6 years the United States has averaged 1.5 percent inflation and many forecasts suggest it will remain below 2 percent for another 2 to 4 years. Accordingly, Evans admitted that the problem Coronado posed - that the public will wonder if the Fed has the wherewithal to keep inflation hovering symmetrically near 2 percent—worries him as well. He noted that such credibility risks would be diminished if the Fed demonstrated its commitment to a symmetric target by applying policies to bring inflation up sooner rather than later.

Referring to Levin's comment about the Taylor Rule having outlived its usefulness, he said he does believe such benchmarks are very important, although only as a gauge to how policy likely would be set during normal times. But the current economy is still very far from being back to business-as-usual. He believes that there is appropriately more humility 
in the paper's view that there is a great deal of uncertainty surrounding the current value of the natural rate of interest and that this uncertainty provides a reason for exercising more caution and delay before beginning to normalize monetary policy.

Regarding quantitative easing, Evans said he was uncomfortable with Kiley's thought that it might not be as effective going forward. He considered it successful and interpreted the success of QE3 as stemming from its being open-ended. The FOMC had told the public it would be committed to hitting its goals and would stay with QE3 until the labor market outlook showed substantial improvement. It was that commitment to goals that he thought was extremely important, and he worried that if the FOMC made a misstep by allowing a premature liftoff, people would wonder about its resolve to achieve its mandates and the Committee would have to work very hard to regain the public's trust.

Finally, Evans agreed with Romer that, historically, once the Fed begins to raise rates it seems to just continue raising them, and the barrier to reversing course appears to be a high one. To him, that is another good reason for delaying the liftoff. In reference to concerns that such delays risk inflationary consequences that the Fed would be slow to address, Evans noted that in fact there have been episodes when the Fed increased rates very strongly when it saw inflation rising too quickly. Two of them occurred in November 1994 and January 1995, when the FOMC increased the funds rate by 75 and 50 basis points, respectively, very big numbers at the time. He believed that it took those actions based on a lack of full confidence that inflationary pressures were under control. The Fed's ability to take such quick action depends, ultimately, on the outlook, and he is confident that the Fed could do that again if its forecasts so dictated. 